\title{
Targeting the Pseudomonas quinolone signal quorum sensing system for the discovery of novel anti-infective pathoblockers
}

\author{
Christian Schütz ${ }^{1,2}$ and Martin Empting ${ }^{* 1,2,3}$
}

\author{
Review \\ Address: \\ ${ }^{1}$ Helmholtz-Institute for Pharmaceutical Research Saarland (HIPS) - \\ Helmholtz Centre for Infection Research (HZI), Department of Drug \\ Design and Optimization (DDOP), Campus E8.1, 66123 Saarbrücken, \\ Germany, ${ }^{2}$ Department of Pharmacy, Saarland University, Campus \\ E8.1, 66123 Saarbrücken, Germany and ${ }^{3}$ German Centre for \\ Infection Research (DZIF), Partner Site Hannover-Braunschweig, \\ Saarbrücken, Germany \\ Email: \\ Martin Empting ${ }^{*}$ - martin.empting@helmholtz-hzi.de \\ * Corresponding author \\ Keywords: \\ anti-infectives; pathoblockers; PQS; Pseudomonas aeruginosa; \\ quorum sensing
}

\author{
Beilstein J. Org. Chem. 2018, 14, 2627-2645. \\ doi:10.3762/bjoc.14.241
}

Received: 31 July 2018

Accepted: 28 September 2018

Published: 15 October 2018

This article is part of the thematic issue "Antibacterials, bacterial small molecule interactions and quorum sensing".

Guest Editor: D. Spring

(C) 2018 Schütz and Empting; licensee Beilstein-Institut. License and terms: see end of document.

\begin{abstract}
The Gram-negative opportunistic pathogen Pseudomonas aeruginosa causes severe nosocomial infections. It uses quorum sensing (QS) to regulate and coordinate population-wide group behaviours in the infection process like concerted secretion of virulence factors. One very important signalling network is the Pseudomonas quinolone signal (PQS) QS. With the aim to devise novel and innovative anti-infectives, inhibitors have been designed to address the various potential drug targets present within pqs QS. These range from enzymes within the biosynthesis cascade of the signal molecules PqsABCDE to the receptor of these autoinducers PqsR (MvfR). This review shortly introduces $P$. aeruginosa and its pathogenicity traits regulated by the pqs system and highlights the published drug discovery efforts providing insights into the compound binding modes if available. Furthermore, suitability of the individual targets for pathoblocker design is discussed.
\end{abstract}

\section{Introduction}

In recent years, attempts to raise public awareness on antimicrobial resistance (AMR) and the large threat that it poses towards modern health standards have been made [1]. It is an alarming notion that at an increasing rate of available treatment options proves ineffective in eradicating bacterial infections [2]. Especially in the case of Gram-negative bacteria, an urgent need for novel medicines has been identified while the pipeline of drug candidates is literally running dry and a desirable renaissance of the golden age of antibiotic drug research in 'big pharma' is currently not to be seen on the horizon $[3,4]$. Nevertheless, some innovative strategies to be explored for their clinical applicability in combating bacterial infections have been devised 
in the last decades mostly driven by academic research [5-7]. In contrast to addressing classical antibiotic drug targets involved in vital processes of the bacterial cell, 'antivirulence' strategies aim at abolishing pathogenic features without affecting cell viability, providing the basis for a lower drug-induced selection pressure $[5,8,9]$. Hence, a reduced rate of resistance development is expected [9]. A clinical proof-of-concept for this unconventional strategy has been provided recently by the approval of the toxin-neutralizing therapeutic antibody bezlotoxumab, which is henceforth in clinical use for pre-emptive treatment of recurring clostridial infections [10]. So, the potential of active principles, which do not kill the bacteria through bactericidal or bacteriostatic effects, but mediate their effect through pathogenspecific action on virulence mechanisms, has been unveiled. This short review focuses on the current knowledge of one particular antivirulence strategy against the important pathogen Pseudomonas aeruginosa, which is based on the disruption of the Pseudomonas quinolone signal quorum sensing system (pqs QS).

\section{Review}

\section{Antimicrobial resistance and clinical relevance of $P$ seudomonas aeruginosa}

$P$. aeruginosa is one of the threatening ESKAPE pathogens and has regularly been attributed with the label 'superbug' [11]. In 2017, the World Health Organization (WHO) has published a priority list for pathogens with urgent need for novel treatment options and carbapenem-resistant $P$. aeruginosa was ranked in the highest category 'critical' [12]. One of the main problems we face regarding this Gram-negative bacterium is that it shows a prominent ability to resist antibiotic treatment via several mechanisms. First and foremost, it possesses an intrinsic resistance to many antibiotics because of the low permeability of its cell wall and due to the action of a number of efflux pumps as well as $\beta$-lactamases. Efflux pumps in particular are nifty molecular machineries consisting of several protein components, which in total span from the inner to the outer side of the cell membrane. Their function is to expel a wide range of xenobiotics, among them antibiotics from the cephalosporin, carbapenem, fluroquinolone and aminoglycoside classes [13]. Through this mechanism, these drugs cannot reach their intracellular targets rendering them ineffective. $\beta$-Lactamases, on the other hand, act specifically on compounds which carry the eponymous cyclic moiety as the activity-driving motif and their genes are found to be encoded on the chromosomes of many $P$. aeruginosa strains. Hence, these antibiotic-inactivating enzymes provide resistance against penicillins and cephalosporins [14].

In addition to these intrinsic capabilities, $P$. aeruginosa is able to acquire resistances toward antibiotics it has come in contact with. These acquired resistances can be the result of spontaneous mutations in genes encoding for the target protein. For example, certain mutational changes within DNA gyrase will lead to lowered susceptibility for fluoroquinolones [15]. Other examples are mutants leading to efflux pump overexpression [15]. If the resistance determinant is located on a transferable plasmid, it can be efficiently spread among bacteria via horizontal gene transfer, which is probably the most frequent mechanism for the development of acquired resistances [15]. In these cases, the resistance determinant is inheritable and passed over to the next generation of bacteria.

Furthermore, a mechanism has been discovered, which is referred to as adaptive resistance and describes the observation that a persistent environmental stimulus can induce non-mutational resistances [15]. Under continuous treatment regimes, the antibiotic itself can of course be the stimulus. But, nutrient deprivation, $\mathrm{pH}$, anaerobiosis, as well as biocides, polyamines, cations and carbon sources could also act as external triggers leading to adaptive resistance. The common effect of these stimuli seems to be an alteration in expression patterns ultimately impacting, e.g., efflux pump or enzymatic activity, as well as cell envelope properties or biofilm formation [15].

All the mechanisms described above help to explain the notion that established chronic $P$. aeruginosa infections are notoriously difficult to eradicate. This ubiquitous opportunistic pathogen is able to cause infections basically in every niche of the human body where it finds enough moisture [16]. Common sites of infection are the respiratory and urinary tracts, the eye and wounds, e.g., those resulting from burn injuries [17]. These occur frequently in hospitalized and especially immunocompromised individuals. Patients with chronic lung diseases like cystic fibrosis (CF) or bronchiectasis have a poor prognosis when $P$. aeruginosa colonisation is detected, as this is usually associated with loss of lung function, morbidity, and mortality [18]. In 2013, it has been estimated, that by the age of eighteen $80 \%$ of the CF patients are Pseudomonas positive. Recently, evidence has been provided that this ratio is reducing [19]. Nevertheless, with progression of age the majority of CF patients will become chronically infected with $P$. aeruginosa and this is still the major cause of death associated with this genetic disorder [20]. Importantly, it has been described that the amount of quinolone-based quorum sensing (pqs QS; vide infra) in those patients correlates with a negative prognosis and might function as a possible biomarker for the severity of the infection [21].

\section{Quroum sensing (QS)}

In general, the term quorum sensing describes a population-density-dependent cell-to-cell communication system making use 
of small diffusible molecules as signalling agents. By this means, pathogenic bacteria can coordinate population-wide changes to expression patterns and regulate concerted group behaviours important in the infection process. Critical pathogenicity traits like the production of virulence factors or biofilm formation are under the control of these systems. Actually, title pathogen makes use of four intertwined QS systems, referred to as las, rhl, pqs, and iqs [22]. These subsystems influence each other establishing an intricate regulatory network with compensatory mechanisms ensuring environmental adaptability and fine-tuned control of associated virulence genes (Figure 1). All four have been studied in the pursuit of quorum sensing inhibitors (QSI) to be used as blockers of $P$. aeruginosa pathogenicity $[11,23]$.

Typically, a QS system of Gram-negatives consists of a transcription regulator, the signal molecules and one or several enzymes involved in the synthesis of the latter. The regulator usually controls the transcription of the biosynthetic enzymes and also functions as a receptor for the signal molecules themselves. As these are actually autoinducers (AIs) and, hence, have an agonistic activity toward their receptor, a positive feedback loop is created. In $P$. aeruginosa three different chemotypes of AIs have been identified, to date: alkyl homoserine lactones (AHLs) used by the las and rhl systems, alkylquinolones (AQs) used by the pqs system and 2-(2-hydroxyphenyl)thiazole-4-carbaldehyde used by the iqs system (Figure 1). Strategies addressing las and rhl have been reviewed elsewhere $[5,11]$, while to date one study on iqs inhibition has been reported [23]. Many drug discovery efforts towards effective pathoblockers have been published based on the design and optimisation of pqs targeting QSI, which is the topic of this review.

\section{The biosynthetic cascade of the pqs QS system}

PQS is the abbreviation for Pseudomonas quinolone signal and actually refers to the signal molecule 2-heptyl-3-hydroxyquinolin-4(1H)-one (Figure 2). This quinolone-based AI and its biosynthetic precursor HHQ (2-heptylquinolin-4(1H)-one) are ligands of a transcription factor called 'multiple virulence factor regulator' (MvfR), also referred to as PqsR. Through interaction with this receptor, HHQ and PQS induce the transcription of a variety of genes including their own biosynthetic enzyme cascade (PqsABCDE). Together with PqsH and PqsL, which are under the control of LasR from the las QS system, these enzymes manage to build up PQS and related molecules from anthranilic acid (Figure 2). This initial building block can be

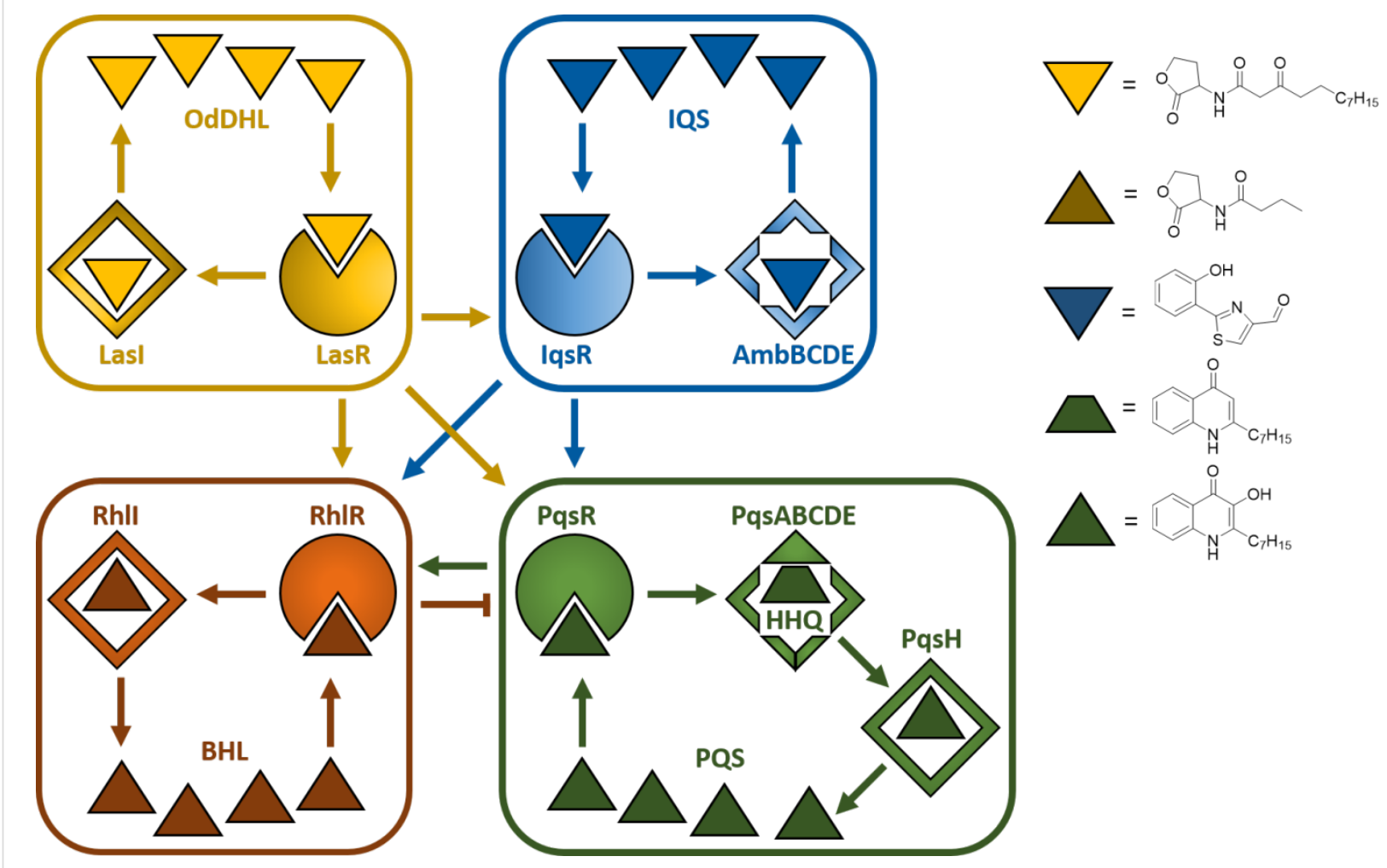

Figure 1: The four quorum sensing systems in $\mathrm{P}$. aeruginosa las, iqs, $r h l$, and pqs. Abbreviations: OdDHL, $\mathrm{N}$-(3-oxododecanoyl) homoserine lactone IQS, integrating quorum sensing signal; BHL, $N$-butyryl-L-homoserine lactone; PQS, Pseudomonas quinolone signal. Positive control is represented by arrows, negative control by blunted arrow. 


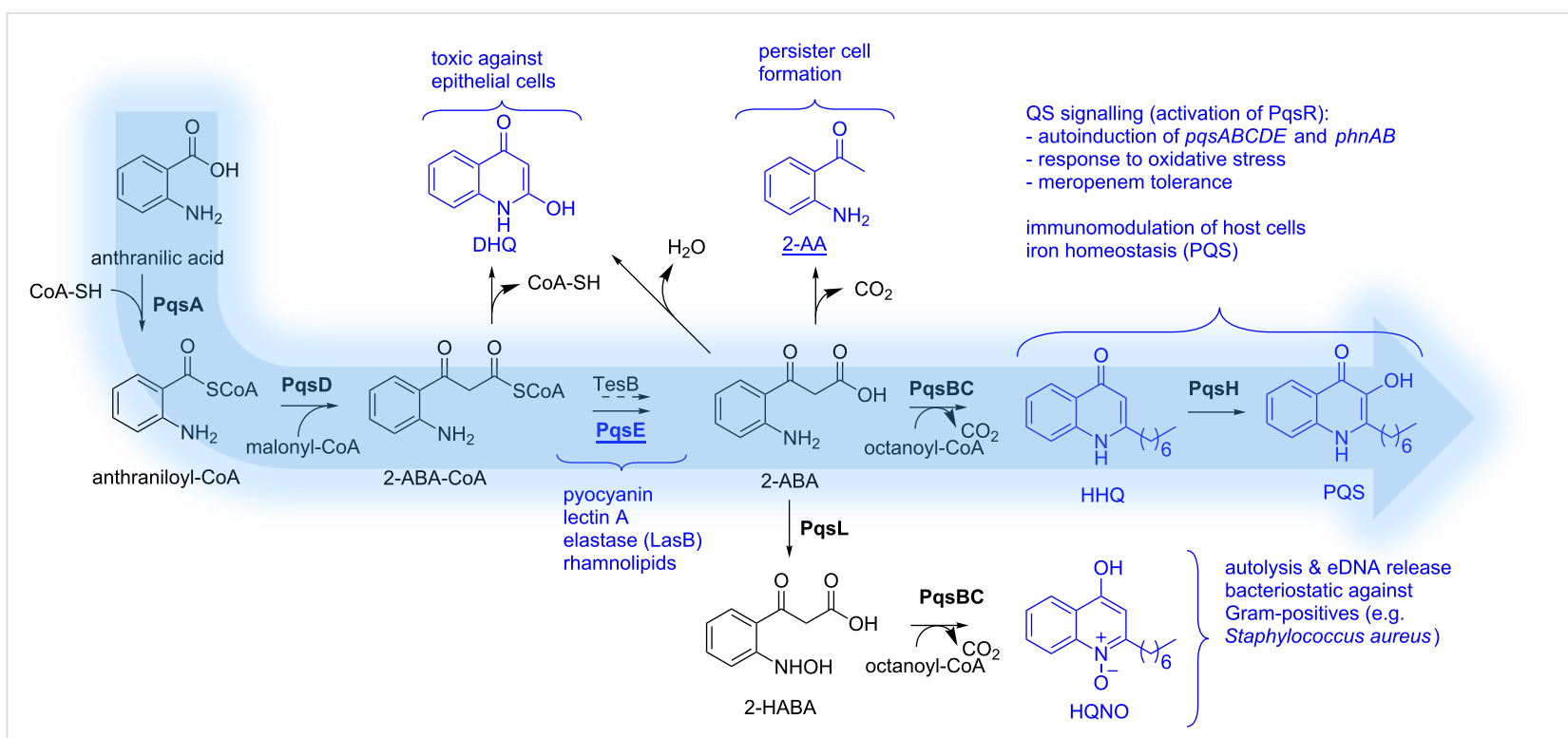

Figure 2: Schematic overview of the PQS biosynthesis and involvement of related metabolites and PqsE in virulence. Effector molecules are highlighted in blue. Enzymes are given in bold. Abbreviations: CoA, coenzyme A; 2-ABA-CoA, 2'-aminobenzoylacetyl-CoA; 2-ABA, 2'-aminobenzoylacetate; DHQ, dihydroxyquinoline; 2-AA, 2'-aminoacetophenone; 2-HABA, 2'-hydroxylaminobenzoylacetate; HHQ, 2-heptyl-4-(1H)-quinolone; HQNO, 4-hydroxy-2-heptylquinoline- $N$-oxide; PQS, Pseudomonas quinolone signal.

provided either through the kynurenine pathway starting from tryptophan or by anthranilate synthases from the PqsR-controlled phnAB operon starting using chorismic acid as a source [24]. Either way, the ligase PqsA starts PQS synthesis by condensing anthranilic acid with coenzyme A [25]. The resulting activated thioester (anthraniloyl-CoA) is then transferred to an active-site cysteine of the $\beta$-ketoacyl-ACP synthase III (FabH)-type enzyme PqsD [26,27]. Subsequently, another CoAactivated substrate comes into play. In analogy to fatty acid synthesis, malonyl-CoA is reacted with the enzyme-bound thioester to yield 2-aminobenzoylacetyl-CoA (2-ABA-CoA) under decarboxylation $[28,29]$. In a next step, the pathway-specific thioesterase PqsE generates 2-aminobenzoylacetate (2-ABA) [29]. It has been shown, that also the broad-specificity thioesterase TesB present in P. aeruginosa can catalyse this reaction [29]. The quinolone core is formed by action of the heterodimeric complex PqsBC. This time, CoA-activated octanoic acid is used to preload an active-site cysteine of PqSC with the fatty acid via a thioester linkage [30,31]. The previously produced 2-ABA is then consumed to from HHQ under decarboxylative condensation [30]. Finally, PQS is produced through hydroxylation of position 3 by the NADH-dependent flavin mono-oxygenase $\mathrm{PqsH}$ [32].

This biosynthetic cascade is also responsible for the generation of the pqs-related metabolites DHQ, 2-AA, and HQNO as well as other AQs having different lengths of the alkyl chain $[29,30]$. Aforementioned enzyme PqsL is needed for the production of HQNO, as it delivers the $N$-oxidised substrate 2-HABA for
PqsBC-mediated condensation with octanoyl-CoA analogous to HHQ biosynthesis [27].

\section{PQS-mediated pathogenicity traits and molecular targets}

$P$. aeruginosa makes use of an arsenal of virulence factors and other pathogenicity traits to overwhelm and colonise the host in the infection process [5] and pqs QS plays a crucial role in the regulation of many of those. It is astonishing, that expression of 182 genes is altered in response to exogenous PQS [33]. Evidence has been gathered, that these effects are mediated either through direct PqsR-dependent action or by PqsR-independent mechanisms, which are most likely due to the iron-chelating as well as antioxidant properties of PQS [33]. Furthermore, it has been unravelled that the thioesterase PqsE, whose biosynthetic function is dispensable due to the presence of alternative thioesterases in P. aeruginosa, is actually also a major effector molecule of pqs QS [33]. Via a yet unknown mechanism, this enzyme regulates 145 genes, while only 30 of these overlap with the PQS regulon. It seems that these two are the main mediators of pqs QS response. In terms of pathogenicity traits, they are involved in the regulation of genes encoding for enzymes responsible for phenazine biosynthesis (pyocyanin production), hydrogen cyanide synthesis, Lectins LecA and LecB and additional genes involved in biofilm formation, enzymes for rhamnolipid synthesis, a Resistance-Nodulation-Cell division (RND) efflux pump encoded by mexGHI-opmD operon, components of Type 3 and Type 6 secretion as well as the exotoxin ExoS, and siderophore synthases [33]. 
In addition to virulence regulation, some remarkable secondary effects have been attributed to the PQS molecule [34]. This autoinducer has been described to mediate iron acquisition, cytotoxicity, outer-membrane vesicle biogenesis, and to exert host immune modulatory effects [34,35]. Interestingly, PQS as well as HHQ are able to interfere with nuclear transcription factor- $\kappa \mathrm{B}$ and hypoxia-inducible factor 1 (HIF-1) signaling pathways and, thus, down-regulate host innate immune systems [36,37]. Other PQS-related metabolites have been shown to have additional effects. HQNO, for example, induces autolysis and release of extracellular DNA thereby promoting biofilm formation and increasing meropenem tolerance [38]. HQNO acts through inhibition of complex III in the respiratory chain of bacteria and mitochondria of eukaryotes and, hence, it can be considered a general cytotoxic agent. DHQ, a shunt product of the PQS biosynthetic pathway, is important for P. aeruginosa virulence in a Caenorhabditis elegans model and also excerts a growth inhibitory effect on epithelial cells [26,39]. Finally, 2-AA has been described to be important for persister cell formation, a very important tolerance mechanism against antibiotic treatment [40].

Among the virulence factors which are directly or indirectly controlled by pqs QS, pyocyanin is one of the most prominent. This redox-active pigment is responsible for the greenishblueish colour of $P$. aeruginosa cultures. It seems that generation of reactive oxygen species is a major mechanism of pyocyanin cytotoxicity [41]. This tricyclic compound is known to induce apoptosis in neutrophils, but also to enhance neutrophil extracellular trap formation $[42,43]$. Both mechanisms impair neutrophil-mediated host defenses. Additionally, it has been hypothesised that pyocyanin functions as an extracellular electron shuttle, contributing to redox homeostasis of $P$. aeruginosa cells in biofilms with anaerobic conditions [44].

Due to these important virulence mechanisms, which are under direct or indirect control of pqs QS, targeting this master regulatory system with small molecular compounds, thereby blocking $P$. aeruginosa pathogenicity, is very attractive. However, this complex network of biosynthetic pathways and effector molecules renders selection of the perfect point for intervention diffi- cult. Due to their rather peripheral role in AQ synthesis, PqsH and PqsL, have not been of significant interest for QSI discovery to date. However, all enzymes of the primary biosynthetic cascade pqsA-E as well as the signal molecule receptor PqsR might be valuable drug targets. Also, agents capable of modulating more than one target could be of interest. The question is, which of these targets and/or combinations asserts the most relevant virulence-attenuated phenotype after QSI treatment.

\section{PqsA inhibitors \\ Anthranilic acid analogues}

Since anthranilic acid (1) serves as a PqsA substrate, the first compound reported to inhibit PqsA is 6-FABA (2, Figure 3), which was able to block this enzyme and successfully suppressed the production of DHQ in PA14 strains at a rather high concentration of $1.5 \mathrm{mM}$. Moreover, it was shown that 6-FABA had no impact on the bacterial growth. Lépine et al. suggested that $\mathbf{2}$ competitively occupies the active site of PqsA [45] and therefore serves as a substrate analogue of AA (1). It was stated that the introduction of electron-withdrawing substituents could prevent activation of the carbonyl group as a CoAester.

In 2017, Witzgall et al. were able to co-crystallize 6-FABAAMP within the $N$-terminal domain of PqsA (Figure 4) [46].

Key interactions involve a water-mediated hydrogen bond between the amino function of the compound and Q162, as in anthraniloyl-AMP. The reason why the fluorinated anthraniloylAMP shows good affinity is the formation of a hydrogen bond of the fluorine with the G279 backbone amide hydrogen and furthermore an interaction with the N7 position of the adenine moiety. Additionally a very typical fluorine/main-chain interaction with G302 could be observed.

Various halogenated derivatives of AA could also reduce HHQ and PQS levels. Especially 4- and 6-CABA $(\mathbf{3}, \mathbf{4})$ showed promising results in the suppression of signal molecules as well as in an in vivo mouse survival model at a concentration of $1.5 \mathrm{mM}$ [47].

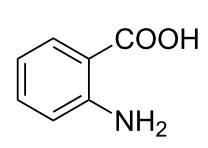

1<smiles>Nc1cccc(F)c1C(=O)O</smiles>

2<smiles>Nc1cc(Cl)ccc1C(=O)O</smiles>

3<smiles>Nc1cccc(Cl)c1C(=O)O</smiles>

4

Figure 3: Anthranilic acid (1) and derivatives thereof (2-4). 


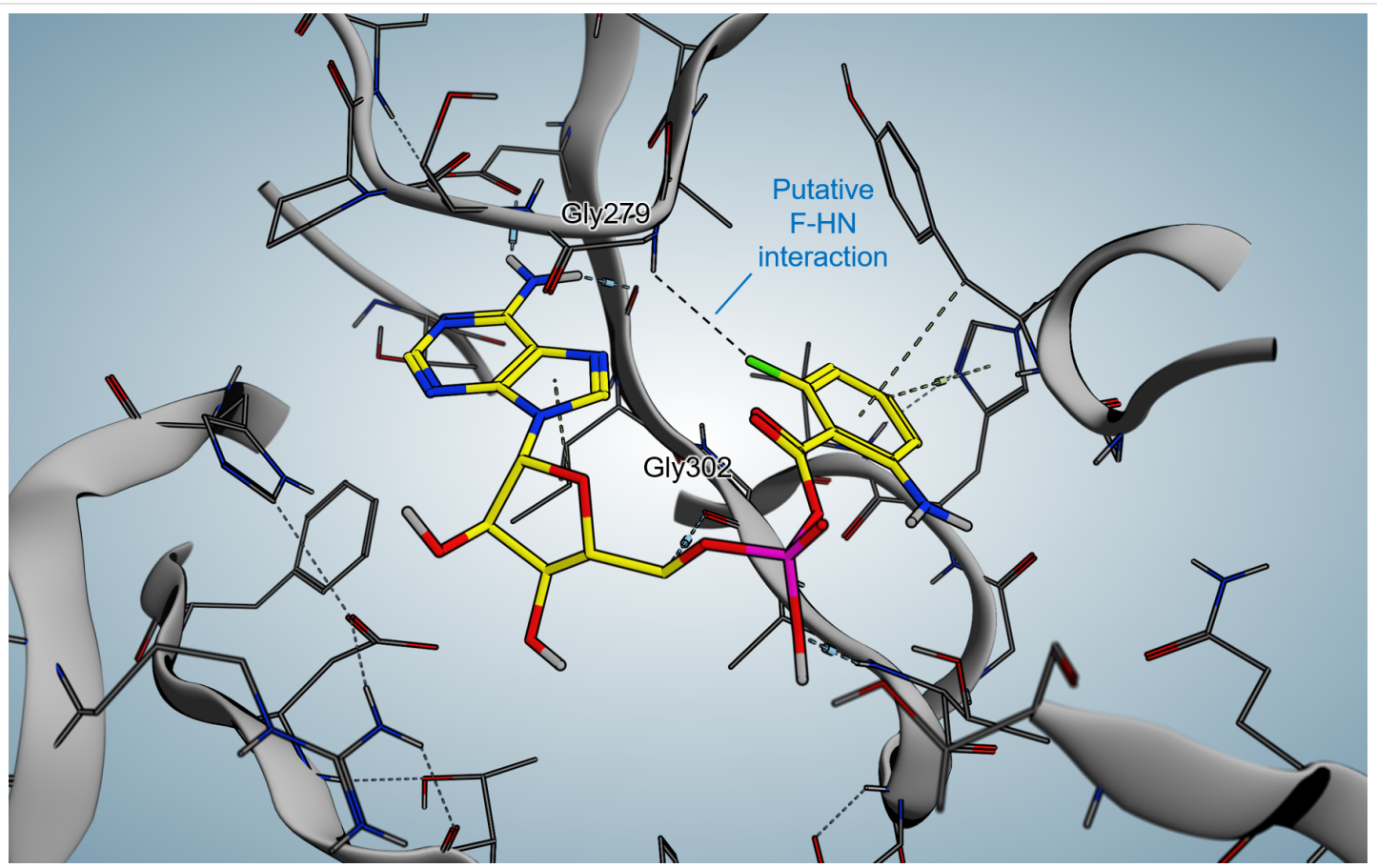

Figure 4: Crystal structure of 6-FABA-AMP in complex with PqsA.

\section{Anthraniloyl-AMP mimetics}

More recently, Ji et al. published two classes of sulfonyladenosine inhibitors, more precisely the sulfamate/sulfamide inhibitors 5-9 and the vinyl sulfonamide inhibitors $\mathbf{1 0}$ and $\mathbf{1 1}$ (Figure 5). While the latter showed very low affinity for the protein, the former displayed $K_{\mathrm{i}}$ values between $88 \mathrm{nM}$ for compound 7 and $420 \mathrm{nM}$ for compound 9. Despite these promising results, the designed molecules were not able to reduce the signal molecules HHQ and PQS at satisfactory levels $\left(300 \mu \mathrm{M}<\mathrm{IC}_{50}<880 \mu \mathrm{M}\right)$.

A plausible reason for this outcome might be low cell penetration and/or efflux pump mechanisms, which was supported by compound accumulation studies [48].

\section{PqsD inhibitors}

PqsD, the second enzyme in the biosynthetic cascade, has been studied intensely by the Hartmann group. Several design strategies have been pursued leading to diverse structural classes of inhibitors (Figure 6). Unfortunately, for none of these compounds an X-ray structure in complex with PqsD has been reported although the apoenzyme as well as a substrate-bound form has been successfully crystallized [49]. Using these coordinates, employing in silico methods allowed proposing plausible binding poses for prototypic analogues of the respective structural classes.

The first reported inhibitors of PqsD were 2-benzamidobenzoic acids [50]. In a pioneering study on the biosynthetic function of<smiles>[R]c1ccccc1C(=O)NS(=O)(=O)CC1OC(n2cnc3c(N)ncnc32)C(O)C1O</smiles><smiles>[R]c1ccccc1/C=C/S(=O)(=O)NCC1OC(n2cnc3c(N)ncnc32)C(O)C1O</smiles>

$5 \mathrm{R}=\mathrm{OH}, \mathrm{X}=\mathrm{O}$

$6 \mathrm{R}=\mathrm{OH}, \mathrm{X}=\mathrm{NH}$

$7 \mathrm{R}=\mathrm{NH}_{2}, \mathrm{X}=\mathrm{NH}$

$8 \mathrm{R}=\mathrm{NH}_{2}, \mathrm{X}=\mathrm{O}$

$9 \mathrm{R}=\mathrm{H}, \mathrm{X}=\mathrm{O}$

Figure 5: Structures of substrate mimetic PqsA inhibitors. 


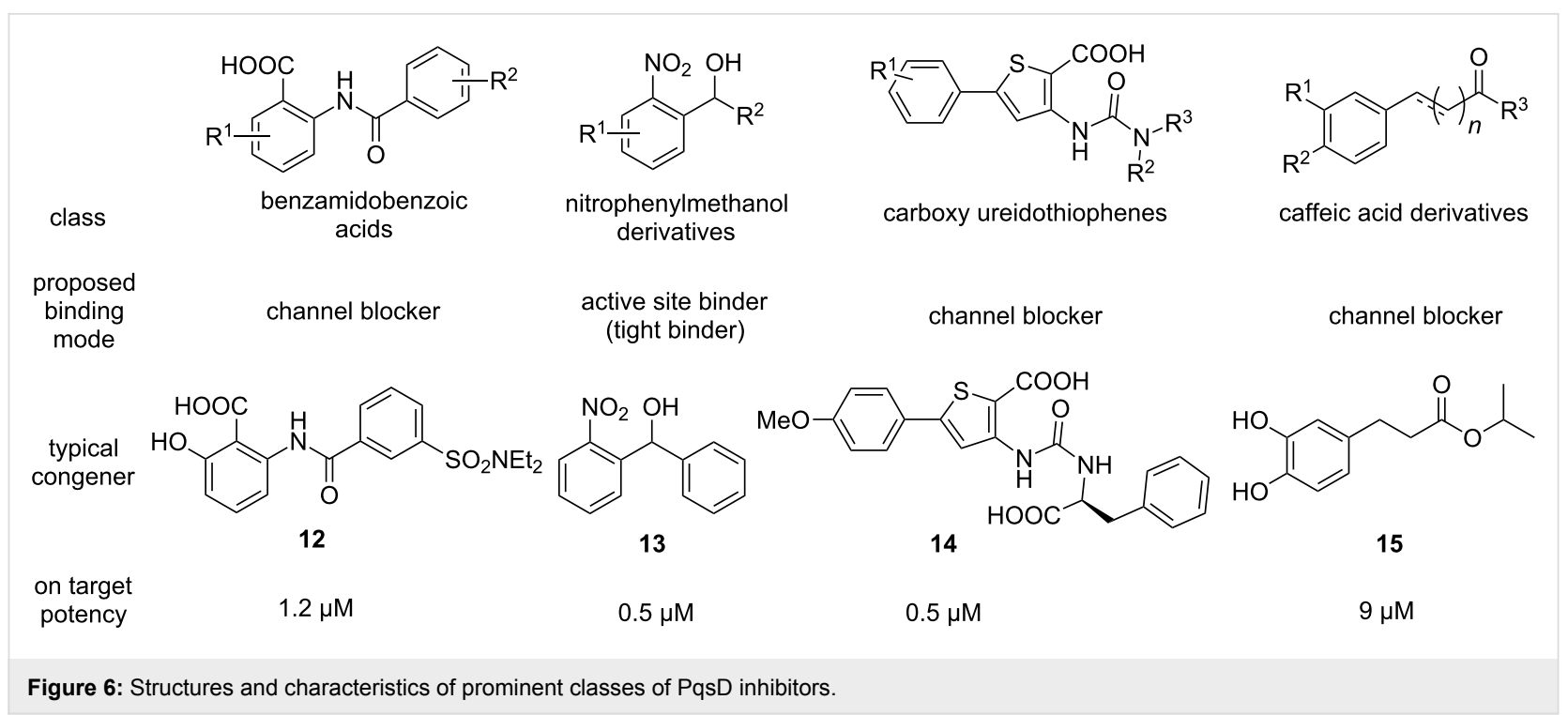

this $\beta$-ketoacyl-ACP synthase III (FabH)-type enzyme, known blockers of $\mathrm{FabH}$ were described to also inhibit this related target [50]. The claim that PqsD is directly responsible for HHQ production by using anthraniloyl-CoA and $\beta$-ketodecanoate as substrates, had to be revised later to also include PqsE and PqsBC as participants in AQ biosynthesis in P. aeruginosa (vide supra) [27]. Nevertheless, this conversion is indeed catalysed by PqsD in vitro and was successfully exploited for devising a valuable assay, which served as an SAR driver for most of the literature-known PqsD-directed projects. Further benzamidobenzoic acid derivatives were explored for their efficacy and a binding mode was proposed based on SPR- and STD-NMR-assisted docking [51]. These inhibitors appeared to bind in the substrate channel in a slightly remote position from the active site cysteine and, hence, termed channel blockers [51]. Optimised hits exhibited a potency in the single-digit micromolar range (12, Figure 6). However, it has been found that similar compounds also showed activity against RNA polymerase, a popular target for the development of new antibiotics $[52,53]$. Hitting such a target would jeopardise the principle of pathoblockers, which should only disarm the bacteria and not kill them. Hence, a follow-up study on PqsD/RNAP selectivity was conducted providing insights into motifs granting selective PqsD inhibition [52].

In a ligand-based approach, nitrophenylmethanol derivatives were identified as fragment-sized inhibitors of PqsD. Initially, these compounds where designed as transition state analogues mimicking the tetrahedral reaction intermediate between PqsD and anthraniloyl-CoA [54]. Upon simplification and rigidification through reduction in size as well as removal of rotatable bonds inhibitor 13 was obtained carrying the characteristic secondary alcohol of this class. Notably, both enantiomers of $\mathbf{1 3}$ show similar potency, but different thermodynamic profiles as measured via isothermal titration calorimetry (ITC) [55]. Despite its low molecular weight, 13 showed tight-binding kinetics and was able to reduce production of HHQ, as well as PQS. Furthermore, it was capable of attenuating biofilm production [54]. All the information gathered via site-directed mutagenesis combined with thermodynamic profiling, as well as surface plasmon resonance (SPR) experiments with and without covalent active site blockade, corroborated that the nitrophenylmethanol class directly binds to the active site near the reactive cysteine of PqsD [55]. This is in line with the initial transition state analogue design principle. Further structural exploration of this class showed that this fragment-like size helps to retain cellular activity [56]. While fragment growing could increase target activity to the nanomolar range, a complete loss of efficacy in the $P$. aeruginosa quorum quenching assays was observed [56]. This highlights a notable issue when addressing intracellular targets of this Gram-negative bacterium, as permeating the outer and inner membrane while escaping efflux and enzymatic deactivation may represent a true challenge.

The elucidation of the binding mode of the nitrophenylmethanol class was then exploited to gain insights into the interaction profile of another chemotype of PqsD inhibitors - the ureidothiophenes (Figure 6) [57,58]. An initial hit showing activity against the enzyme in the single-digit micromolar range was studied using a tailor-made SPR experiment including truncated and elongated derivatives as well as nitrophenylmethanolbased active-site blockers of different size as competitors. These experiments combined with molecular docking (Figure 7) led to the postulation of a plausible binding pose characterising the ureidothiophenes as channel blockers. This model was suc- 


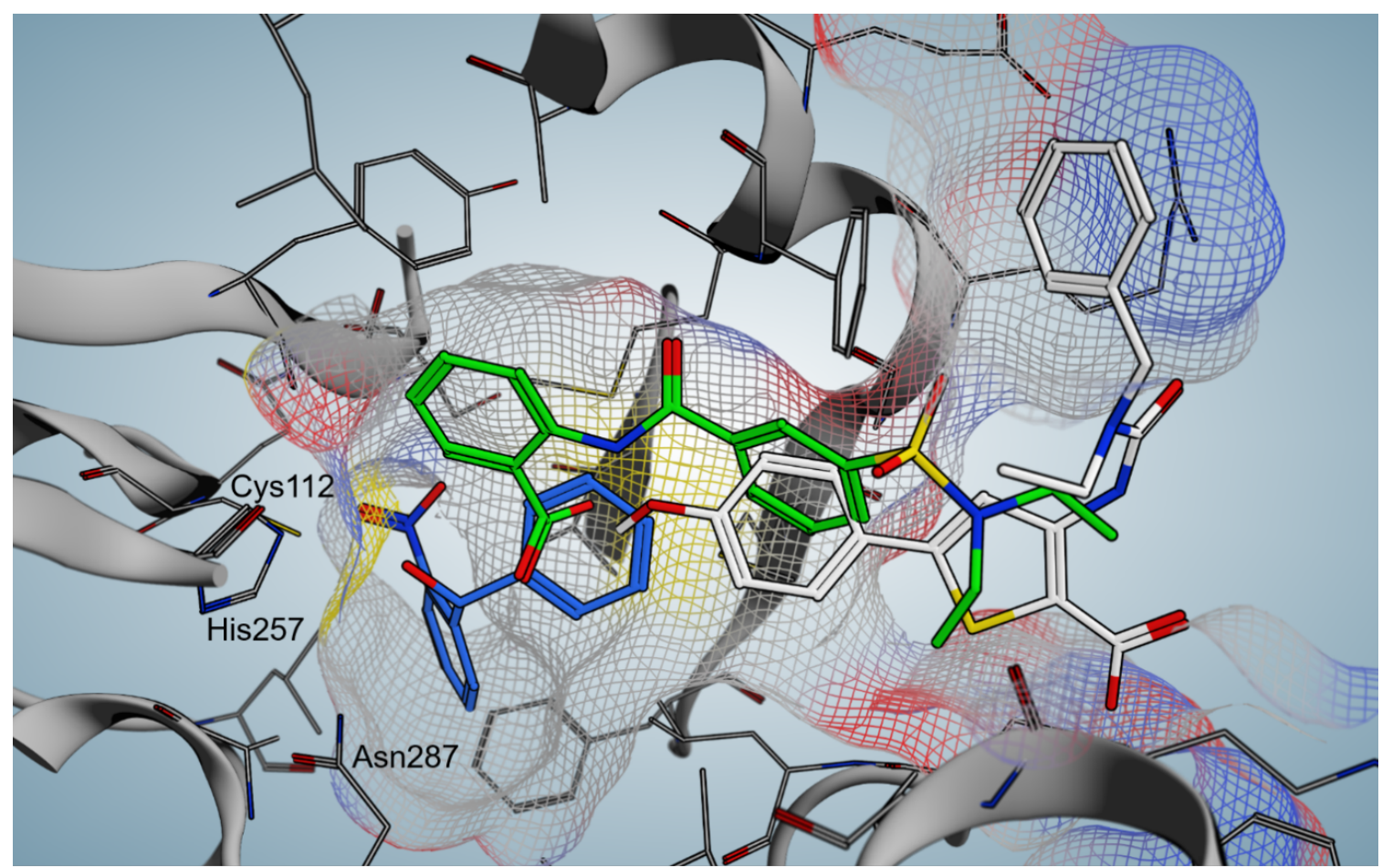

Figure 7: Comparison of docking poses of three prototypic PqsD inhibitors: benzamidobenzoic acid derivative 12 (green), nitrophenylmethanol derivative 13 (blue), carboxy ureidothiophene derivative 14 (white). Active site residues are labelled and the surface of the substrate tunnel is indicated by a mesh.

cessfully used for further optimisation attempts and nanomolar potency in the enzyme assay was achieved (14, Figure 6) $[57,58]$. Notably, a nucleophilic warhead could be introduced specifically reacting with the active-site cysteine through elongation into the substrate tunnel [57]. The binding models of the ureidothiophene and nitrophenylmethanol classes even allowed for the generation of a merged inhibitor [58]. One major liability of this class, however, was the general inefficacy in whole cell assays, which could not be improved, even through the attachment of a cell-penetrating peptide sequence [58].

One additional class, which did show cellular activity, was based on a catechol scaffold [59]. In analogy to the successful discovery of PqsD inhibitors starting from known FabHtargeting compounds (vide supra), ligands of another enzyme with high similarity to the signal molecule synthase were investigated. Here, substrates of chalcone synthase CHS2 from Medicago sativa were tested for their ability to block PqsD function. Indeed, caffeic acid analogues, such as $\mathbf{1 5}$, were identified as hits and further characterized as channel blockers as described before [59].

Further interesting starting points for the discovery of PqsD inhibitors have been provided by a dedicated screening campaign involving fragment-based hit discovery, in silico screening and a similarity-guided approach starting from FabH inhibitors [60]. The most potent hit $\mathbf{1 6}$ of this study showed activity in the nanomolar range (Figure 8). Furthermore, a tetrazolopyrimidinone scaffold 19 has been reported to inhibit PqsD through a putative blockade of the CoA binding site [61].

The Böttcher group used a library of HHQ as well as PQS analogues to screen for PqsD inhibition [62]. To this end, a novel competition assay employing 'clickable' active-site-labelling probes was developed. These compounds contain terminal alkyne moieties, which can be exploited for straightforward decoration via copper(I)-catalyzed alkyne-azide cycloaddition (CuAAC), the prototypic click reaction. This facilitated the discovery of novel PqsD-targeting compounds through CuAAC-mediated conjugation of a fluorescent dye (Figure 9) [62].

Finally, Sangshetti et al. reported the discovery of linezolid-like Schiff bases, which showed promising anti-biofilm activity in the double-digit micromolar range [63]. Notably, their potency in attenuating biofilm formation was more pronounced than ciprofloxacin and linezolid itself. A docking study suggested PqsD to be the target of these compounds like 23 (Figure 10), although this remains speculative. 
<smiles>Cc1ccc(S(=O)(=O)c2cc(O)c3ccccc3c2O)cc1</smiles>

16

hit identification method proposed binding mode

on target potency target similarity (FabH inhibitor)

channel blocker

$0.2 \mu \mathrm{M}$<smiles>CN1CCNC1=S</smiles>

17

fragment screening

channel blocker

$2.6 \mu \mathrm{M}$ channel blocker<smiles>O=c1[nH]ccc2nnnn12</smiles>

19

virtual screening

purine base mimic

channel blocker

Figure 8: Structures and characteristics of hits against PqsD identified through different methods.<smiles>CC(C)(C)c1c/c(=N\O)c2ccccc2[nH]1</smiles>

20

\begin{abstract}
type
\end{abstract}
HHQ derivative

activity in
competition assay fully active at $240 \mu \mathrm{M}$<smiles>CC(C)(C)C(C)(C)c1sc2ccccc2c(=S)c1O</smiles>

21

PQS derivative

fully active at $24 \mu \mathrm{M}$<smiles>C#CCCNC(=O)CCl</smiles>

22

click probe used for competition assay

covalent active-site binder

Figure 9: $\mathrm{HHQ}$ and $\mathrm{PQS}$ analogues as $\mathrm{PqsD}$ inhibitors and chemical probe used for screening.<smiles>Fc1cc(/N=C/c2cc3ccccc3nc2Cl)ccc1N1CCOCC1</smiles>

linezolid-like Schiff base

Figure 10: Structure of PqsD-targeting biofilm inhibitor derived from linezolid.

\section{PqsE inhibitors}

The pathway-specific thioesterase PqsE is not only responsible for hydrolyzing 2-ABA-CoA to form 2-ABA, but moreover also regulates bacterial virulence [29]. It has been shown that PqsE is a key effector of the pqs system and required for full $P$. aeruginosa virulence. One of its most prominent functions is the upregulation of pyocyanin, which is mediated through the $r h l$ system. Notably, PqsE can still exert its function in absence of an active pqs QS [64,65]. Its important role in virulence regulation renders this enzyme an attractive target for pathoblockers.

In 2016, Zender et al. reported their attempt to inhibit PqsE through fragment-based screening. In order to block the thioesterase activity of the enzyme, a library of 500 fragments was screened via differential scanning fluorimetry (DSF) and the hit fragments 24-26 (Figure 11) were further validated using isothermal titration calorimetry (ITC) [66]. Binding to PqsE could be confirmed with $K_{\mathrm{D}}$ values of $0.9 \pm 0.3 \mu \mathrm{M}$ for $\mathbf{2 4}$ and $19.6 \pm 3.7 \mu \mathrm{M}$ for $\mathbf{2 6}$.

The highly enthalpy-driven binding indicates a specific noncovalent interaction of $\mathbf{2 4}$ to the protein. To further investigate the binding mode of the hit fragments in the protein crystallization experiments were performed. Since the native substrate 2-ABA- 
<smiles>O=C(O)c1ccccc1-c1cccnc1</smiles>

24<smiles>O=C(O)c1ccccc1-n1cccc1</smiles>

25

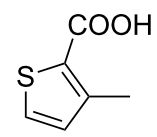

26
Figure 11: Fragment-based PqsE-inhibitors 24-26.

CoA shows a short half-life, the reaction product 2-ABA was used as a surrogate to compare its binding mode with that of the hit fragments.

Even though the screening hits occupy the same binding site as the native cleavage product 2-ABA, the binding mode is different. The fragments bridge the two metal atoms in the binuclear active center via a water molecule in contrast to 2-ABA, where the carboxylate occupies this position (Figure 12). Moreover

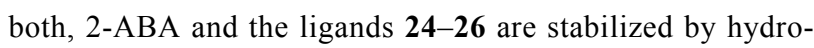
phobic interactions. Additionally, compounds $\mathbf{2 4}$ and $\mathbf{2 5}$ are interacting with a histidine (His71) sidechain via $\pi$-stacking. For the thiophene-containing fragment $\mathbf{2 6}$ a $\pi-\pi$ interaction of the sulfur with Phe195 can be observed.

In vitro evaluation was performed using a combined PqsDE assay due to the aforementioned instability of 2-ABA-CoA which in this scenario is generated in situ from anthraniloyl-
CoA via PqsD-mediated condensation with malonyl-CoA. The hit fragments were able to block the thioesterase in the micromolar range (e.g., $\mathrm{IC}_{50}(\mathbf{2 4})=25 \pm 4 \mu \mathrm{M}$ ). When assessing the hits on Pseudomonas cultures, thioesterase inhibition remained, whereas none of the compounds had any impact on pyocyanin production at a concentration of $500 \mu \mathrm{M}$. This means that the regulatory function of PqsE is not linked to its hydrolase function. Since the regulatory function of the enzyme is not associated to its active site, it was hypothesized that it might be involved in a macromolecule-macromolecule interaction, e.g., protein-protein or protein-DNA/RNA interaction, while the exact molecular mechanism remains unclear. Even though Zender et al. were not able to attenuate PA virulence via blockage of PqsE, important new insights on this target were made. The discovery that pathoblockers targeting PqsE assumedly may not need to target the active site of the enzyme, but rather a different pocket or surface. To this end, further research on the exact molecular mechanism of the regulatory activity of PqsE is needed.

\section{PqsBC}

The small molecule 2-AA (27), which is also a secondary metabolite generated in the AQ biosynthesis pathway, was reported to inhibit PqsBC [31]. In a PqsBC-based biochemical assay it showed an $\mathrm{IC}_{50}$ in the micromolar range and was proven to reduce virulence in an acute mouse infection model [67].
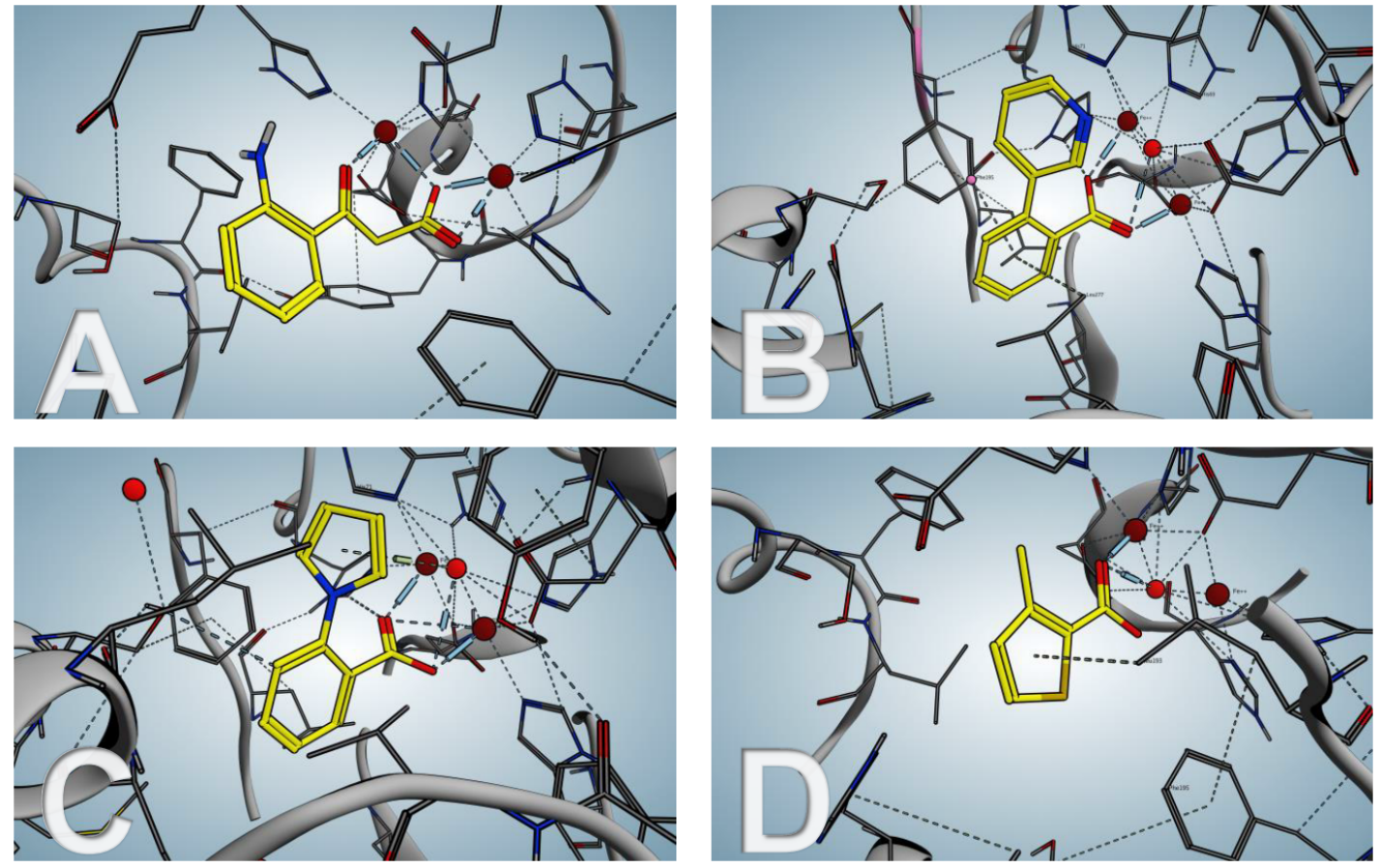

Figure 12: PqsE co-crystal structures. (A) native product 2-ABA; (B-D) hit fragments 24-26. 
In 2017, Maura et al. synthesized inhibitors based on a benzimidazole scaffold (Figure 13) [68]. Starting from a PqsR inhibitor, changes of the electronic properties on the benzimidazole by introducing an electron-donating group led to a higher PqsBC inhibitory activity, while decreasing the affinity to PqsR (compound 28).

Nevertheless, it was shown that blockage of PqsBC leads to a reduction of HHQ but an accumulation of DHQ, which is reported to be toxic for epithelial cells, and 2-AA, which is involved in formation of persister cells [69]. In the same work, compounds 29 and $\mathbf{3 0}$ were evaluated. Compound 29 was first reported in a study aiming at the design of PqsD inhibitors, showing only very weak activity against this target. However, it showed surprisingly good effects on signal molecule production in cell-based assays. Later it was found that this compound actually gains its cellular activity through inhibition of PqsBC $[56,70]$. As already expected from previous results these compounds also showed a strong increase in 2-AA and DHQ production, while not affecting the overall production of AQ's.

\section{PqsR}

In 2017 Kamal et al. investigated the structure-functionality relationship of compounds targeting PqsR. They differentiated between agonists, neutral agonists, inverse agonists and agonistic/antagonistic mixed profile compounds. It was shown that only inverse agonists were able to reduce transcriptional levels below basal and with that the production of pyocyanin. This implies that the aim is to search rather for inverse agonists than for antagonists [71].

\section{Ligand-based design}

Following a ligand-based approach Lu et al. modified the native PqsR ligand HHQ (31) by introducing a strong electron-withdrawing nitro group in the 6-position (compound 33) [72]. While displaying an $\mathrm{IC}_{50}$ of $51 \mathrm{nM}$ in an E. coli-based reporter gene assay, $\mathbf{3 3}$ was also able to reduce pyocyanin production to $44 \%$ at $15 \mu \mathrm{M}$. Further investigations showed that when conducting the reporter gene assay in $P$. aeruginosa instead of using the heterologous $E$. coli system activity of $\mathbf{3 3}$ was drastically reduced (only $60 \%$ inhibition at $10 \mu \mathrm{M}$ ). The reason for this drop in activity was the cell-mediated oxidation of the 3 -position of the quinolone core through action of the P. aeruginosa enzyme PqsH (Figure 14), turning the inverse agonist $\mathbf{3 3}$ into a strong agonist $\mathbf{3 4}\left(\mathrm{EC}_{50}=2.8 \mathrm{nM}\right)$.

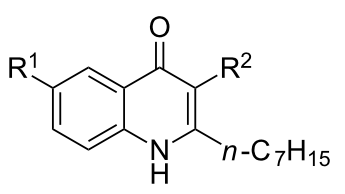

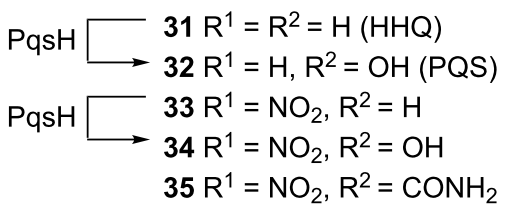

Figure 14: Native PqsR ligand $H H Q$ (31) which is converted into $P Q S$ (32) by PqsH and synthetic inhibitors $\mathbf{3 3}$ and $\mathbf{3 5}$, former is also converted by $\mathrm{PqsH}$ into the strong agonist 34 .

This phenomenon was overcome by blocking the metabolic susceptible 3-position with various functional groups resulting in $\mathbf{3 5}$ which showed good activity in both $E$. coli $\left(\mathrm{IC}_{50}=35 \mathrm{nM}\right)$ and $P$. aeruginosa $\left(\mathrm{IC}_{50}=404 \mathrm{nM}\right)$ based reporter gene assays. Furthermore, this compound was able to inhibit pyocyanin production with an $\mathrm{IC}_{50}$ of $2 \mu \mathrm{M}$ and HHQ levels were reduced to $54 \%$ at a concentration of $15 \mu \mathrm{M}$. Additionally the Hartmann group demonstrated that $\mathbf{3 5}$ enables survival of PA14-infected Galleria melonella larvae [73]. Moreover, the optimised compound also benefited from a decreased clogP value compared to the parent compound 33, which is reflected in an improved solubility [74]. In a recent publication by Kamal et al. the pharmacological profiles of several alkylquinolone compounds were investigated in a structure-functionality relationship manner, resulting in four different profiles: (a) agonists, (b) antagonists, (c) inverse agonists and (d) biphasic modulators. These studies revealed that pyocyanin production is only decreased significantly when the QS modulators are inverse agonists. It was hypothesized that the already mentioned 3-position is crucial for the functionality. Depending on the groups installed in this position and, hence, the different ligand-protein interactions they introduce, com-<smiles>CC(=O)c1ccccc1N</smiles>

27<smiles>Cc1ccc2[nH]c(SCC(=O)Nc3ccc(Br)cc3)nc2c1</smiles>

28<smiles>O=[N+]([O-])c1ccccc1C(O)c1ccoc1</smiles>

29

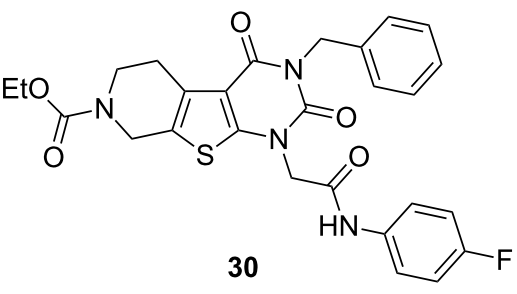

Figure 13: Structurally diverse PqsBC-inhibitors 27-30. 
pounds are either agonists, antagonists, or inverse agonists. This hypothesis was in accordance with a study made by Shanahan et al. who synthesized various other C-3 substituted analogs [75].

Ilangovan et al. discovered a quinazoline scaffold as another class of ligand-based hit compounds. Based on the C9-congener of HHQ several substituted 2-alkyl-4(H)-quinazolines were synthesized. The most potent compound 36 (Figure 15) showed micromolar inhibition in $P$. aeruginosa and was able to decrease pyocyanin levels down to less than $0.5 \mu \mathrm{g} / \mathrm{mL}$ at $100 \mu \mathrm{M}$. Furthermore, AQ signal molecules could also be suppressed. The crystal structure of the PqsR co-inducer binding site in complex with $\mathbf{3 6}$ was solved at $2.95 \AA$ resolution (Figure 16), as well as a co-crystal structure of the native HHQ C9-congener NHQ [76] demonstrating a competitive binding mode.

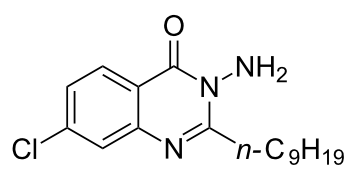

36

Figure 15: Quinazolinone inhibitor 36 (QZN).

When compared to the native ligand NHQ, 36 shows similar hydrophobic interactions (Figure 16). In addition, the chlorine is able to occupy a vacant sub pocket. A hydrogen bond is found between the backbone oxygen of $\mathrm{L} 207$ and the $3-\mathrm{NH}_{2}$ hydrogen atoms. Interestingly, adding the chlorine substituent in 7-position of PQS leads to a 135 times more potent agonist, indicating the importance of the vacant sub pocket next to T265. This also indicates that the quorum quenching activity of $\mathbf{3 6}$ depends on slight conformational changes. The L1 loop main chain and a rotation of the T265 side chain are hypothesized to be important for antagonistic/inverse agonistic functionality of PqsR-targeting QSIs.

More recently the same group used docking studies to select compounds from a quinolone-based compound library (Figure 17). The best fitting compounds 37-40 were then evaluated in a whole bacterial cell-based $P$. aeruginosa screening<smiles>[R]C(=O)N1N=C(c2ccccc2)C[C@H]1c1cccc(Nc2ccnc3cc([R])ccc23)c1</smiles>

$$
\begin{aligned}
& 37 R^{1}=C l, R^{2}=H \\
& 38 R^{1}=C l, R^{2}=M e \\
& 39 R^{1}=C F_{3}, R^{2}=H \\
& 40 R^{1}=C F_{3}, R^{2}=M e
\end{aligned}
$$

Figure 17: Structures of best fitting compounds $37-40$ obtained from docking studies.

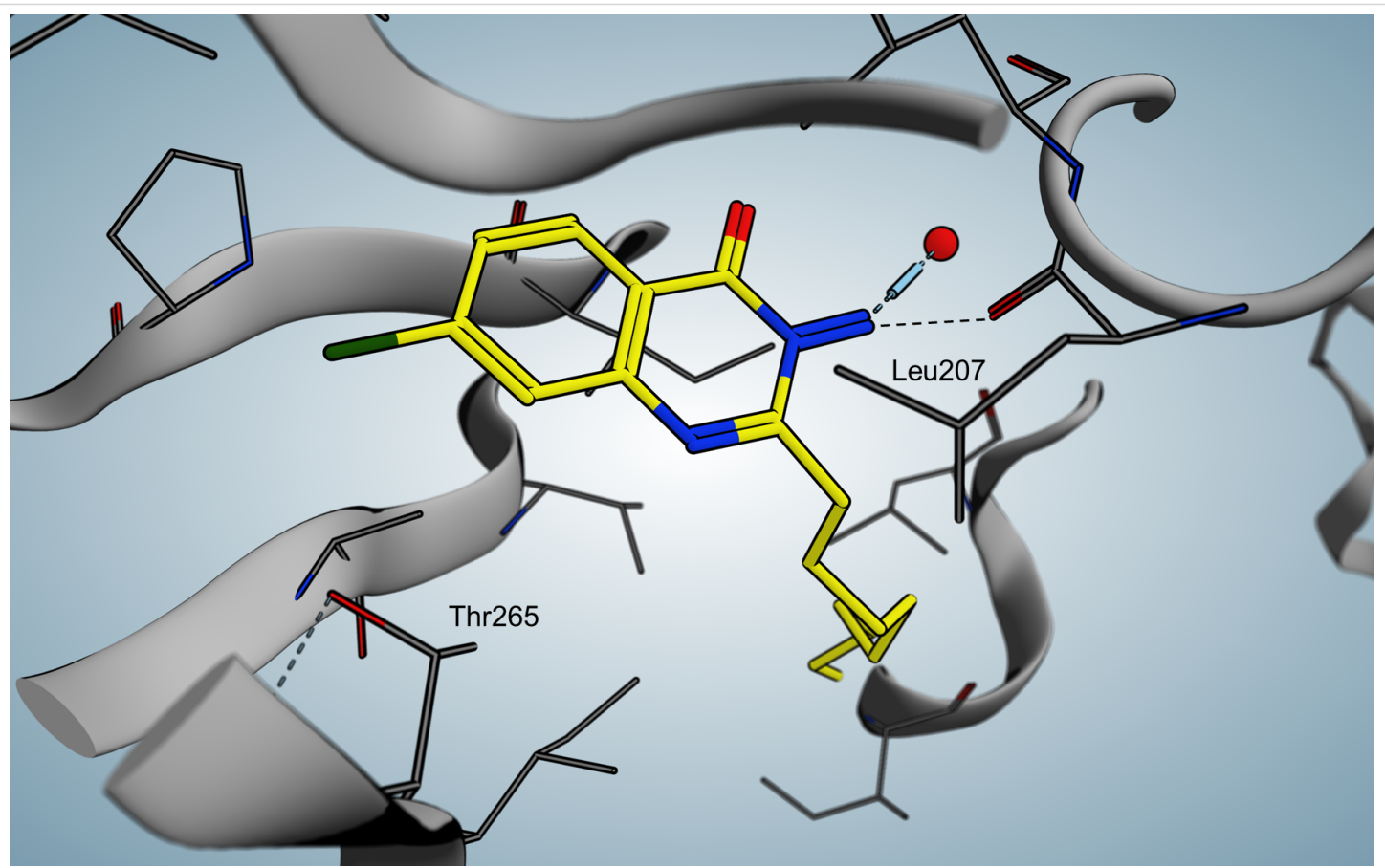

Figure 16: Crystal structure of QZN (36) in complex with $P q s R{ }^{C B D}$. 
with $\mathrm{IC}_{50}$ values in the low micromolar range. Additionally, they showed that compound $\mathbf{3 7}$ emerged as the most potent inhibitor of this series.

Compounds $\mathbf{3 7}$ and $\mathbf{3 9}$ furthermore exhibited inhibition of HHQ, PQS and HQNO production in PAO1 strains when treated with $3 \times \mathrm{IC}_{50}$, whereas in PA14 a strong decrease in activity could be observed, especially for $\mathbf{3 9}$.

\section{Benzamide-benzimidazole (BB) series}

In 2014, Starkey et al. performed a high-throughput whole-cell screening and identified the benzamide-benzimidazole (BB) motif as a promising scaffold for the inhibition of PqsR [77]. Starting from 41, which was not only able to suppress expression of AQs but also completely blocked pyocyanin production at a concentration of $10 \mu \mathrm{M}$. Various analogues were synthesized resulting in compound $\mathbf{4 2}$ (M64), where similar as in the quinolones described by Lu et al., introduction of the electronwithdrawing nitro function led to very potent inverse agonist (Figure 18) [72]. M64 (42) proved a very potent inhibitor of HAQ and pyocyanin production at $1 \mu \mathrm{M}$.

Further investigations revealed that M64 (42) also reduces 2-AA levels leading to a decreased rate of persister cells. The compound also proved to be active in burn wound and lung infection models in mice and increased survival rates especially when applied in combination with sub-therapeutic doses of ciprofloxacin. In an analytics-driven study by Allegretta et al., the compound was further profiled regarding suppression of the PQS-related metabolites DHQ, 2-AA, HHQ, PQS and HQNO. In brief, this study demonstrated that PqsR is an excellent target for potent QSI compounds effectively suppressing AQ levels and 2-AA production at reasonable concentrations [69]. Lately, Maura and Rahme were able to demonstrate the effect of M64 (42) on biofilm formation [78]. Biofilm biomass was drastically reduced when treated with 1 and $10 \mu \mathrm{M}$ of $\mathbf{4 2}$ compared to the untreated PA14 control. Function of PqsR is involved in regulation of HQNO-mediated autolysis and eDNA release, which has been reported to be important for antibiotic tolerance of biofilm-inheriting bacteria. Hence, Rahme and co-workers investigated the effect of their compound $\mathbf{4 2}$ on the ability to improve antibiofilm effects of two clinically relevant drugs.
When growing biofilms for $48 \mathrm{~h}$ in presence or absence of M64 (42), followed by treatment of $10 \mu \mathrm{g} / \mathrm{mL}$ of meropenem or tobramycin for $24 \mathrm{~h}$, the activity of the otherwise ineffective antibiotics could be restored. Especially in the case of meropenem, which did not have any effects at all on biofilm viable cells, 42 lead to remarkable results. In 2018, Kitao et al. solved the crystal structure for PqsR ligand binding domain in complex with M64 (42) with a resolution of $2.65 \AA$ (Figure 19), unravelling the exact interactions of the compound with the protein [79].

Indicated key interactions are $\pi$-stacking of Y258 with the phenoxy moiety in the tail region and a hydrogen bond formed between the Q194 side chain and the carboxamide in the linker area. Furthermore the benzimidazole core shows hydrophobic contacts with isoleucins 149 and 236. More hydrophobic interactions were observed in the tail region, in particular with leucins 189 and 208 as well as Y258. Mutations at these specific residues indicated that the $\pi-\pi$ interactions of $\mathrm{Y} 258$ are crucial for M64's full inhibition with respect to pyocyanin production, which was only weakly inhibited in an Y258M $P$. aeruginosa mutant strain. The importance of the phenoxy substitutent was further supported by a congener of M64 that lacks this motif and therefore is unable to be involved in $\pi$-stacking resulting in a nine-fold increased $\mathrm{IC}_{50}$ value compared to M64. Even though there is no specific interaction observed for the nitro function it is crucial for the activity and thus believed to form an instable H-bond with T265. The Rahme group already demonstrated in a former ITC assay that M64 is directly bound in the PqsR LBD [77]. However, they were also suggesting inverse agonistic effect of M64 based on mutation experiments [79]. Moreover an in vivo cross-linking assay of full-length PqsR and a corresponding I68F mutant was carried out leading to the suggestion that upon binding of M64 the protein stability might be increased. Based on these results it was proposed that M64 induces a change in conformation of the PqsR-DNA binding domain, whereas the LBD is not affected extensively.

\section{Aryloxyacetindoles}

Spero Therapeutics further optimized M64 (42), firstly by changing the phenoxyphenylamide into a carbonyl-linked

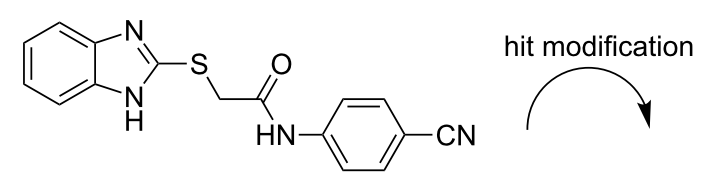

41

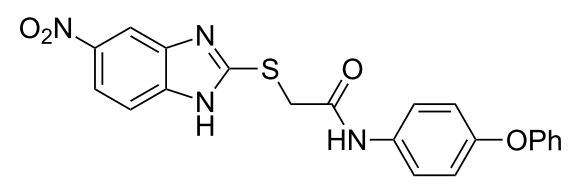

$42(\mathrm{M} 64)$

Figure 18: Initial hit 21 and optimized compound 42 (M64). 


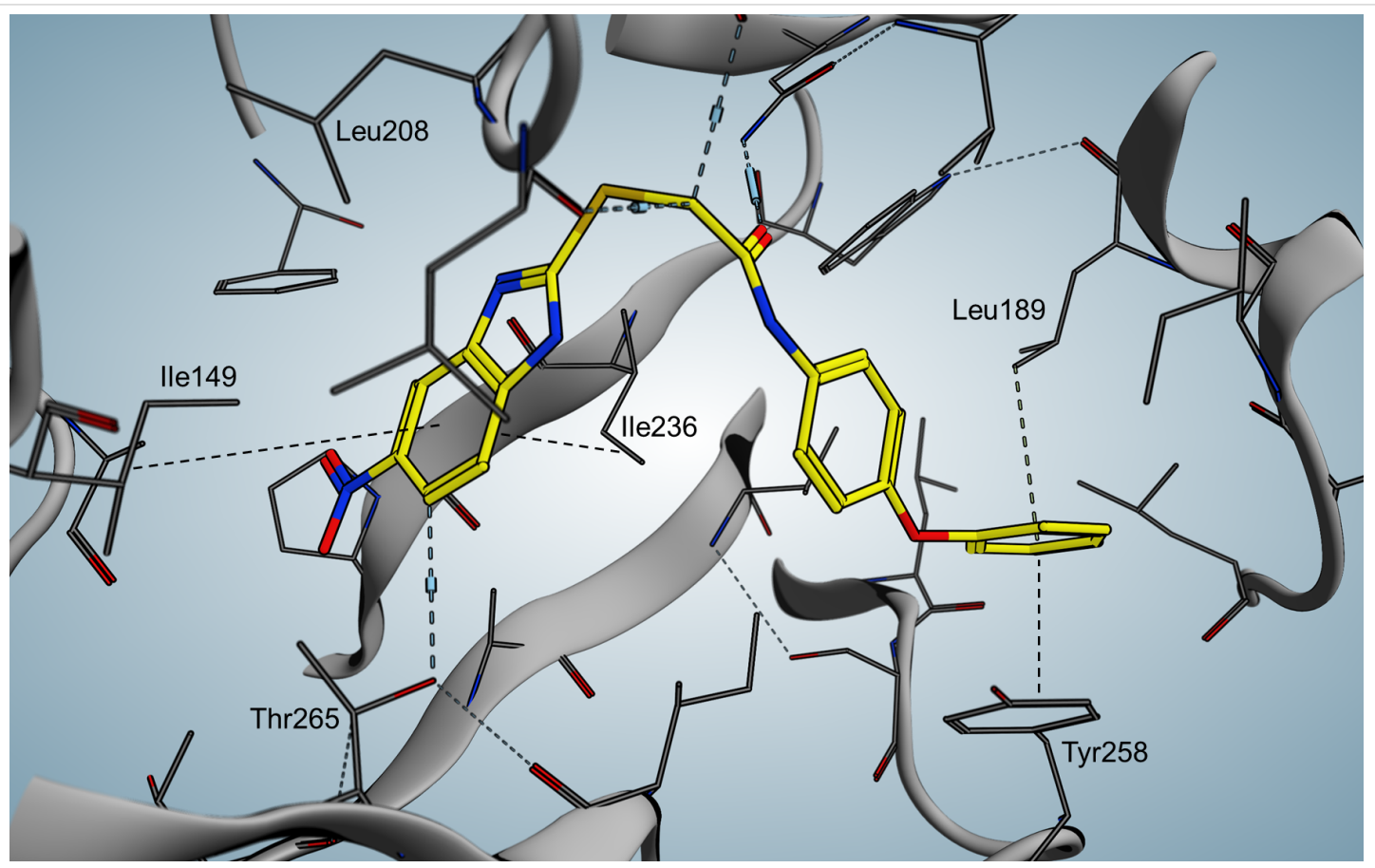

Figure 19: Co-crystal structure of $M 64$ (42) with $\mathrm{Pqs} \mathrm{R}^{\mathrm{LBD}}$.

indole containing a hetarylether (43) [80]. Afterwards they varied the linkage of the benzimidazole moiety (compound not shown) [80]. In a follow-up patent they generated PqsR inhibitor 45 as a front-runner compound [81], in which the benzimidazole headgroup was replaced by a substituted naphthalene bearing a carboxamide, in analogy to a fragment $\mathbf{4 4}$ of Zender et al. [82] and similar to the carboxamide-decorated nitro-quinoline scaffold described by Lu et al. (Figure 20) [73].

Compound 45 was highly potent in inhibiting pyocyanin production (stated $\mathrm{IC}_{50}$ in a range of $50-250 \mathrm{nM}$ ) and was furthermore able to suppress PQS and HHQ production $\left(50 \mathrm{nM}<\mathrm{IC}_{50}<250 \mathrm{nM}\right)$. In a murine thigh infection model using PA14, target engagement was demonstrated in vivo measuring PQS and HHQ levels from the corresponding tissues after treatment. Compound $\mathbf{4 5}$ was able to reduce PQS and HHQ levels to $50 \%$ and $40 \%$, respectively, 12 hours post-infection. Up to now no further optimization or development of these compounds has been reported.

\section{Fragment-based design}

In 2012 Klein et al. obtained the benzamides $\mathbf{4 6}$ and $\mathbf{4 7}$, as well as the hydroxamic acid $\mathbf{4 8}$ as hits within an SPR screening, which were further evaluated in ITC experiments in order to have a clearer view on the thermodynamic parameters (Figure 21). The antagonists displayed activity in a low doubledigit $\mu \mathrm{M}$ range, but had only a marginal impact on the production of the virulence factor pyocyanin [83].
Further SPR screenings afforded hits 49-51 with $\mathrm{EC}_{50}$ between 7.5-17.8 $\mu \mathrm{M}$. When compared to the benzamide class, compound 49 shows no significant increase in affinity to the target receptor but is able to inhibit pycocyanin formation by $46 \pm 9 \%$ at a concentration of $250 \mu \mathrm{M}$, and is capable of reducing the AQ's HHQ and HQNO up to $43 \pm 3 \%$ at the same concentration [82]. With these fragments in hand further growing and subsequent linking or merging may open new avenues for the generation of new drug-like PqsR inverse agonists.

\section{Dual target QS inhibitors PqsBC/PqsR}

In an initial target assessment, Maura et al. found that compound 52 showed an ambiguous profile. This raised the question if this compound class could target additional targets of the PQS-system besides PqsR [68]. Experiments with a PqsR isogenic mutant strain revealed that $\mathbf{5 2}$ inhibits HHQ and PQS production, while raising 2-AA levels, pointing at $\mathrm{PqsBC}$ as a second target, which was corroborated via SPR studies. When exchanging the chlorine to bromine 53 a high PqsR activity was obtained while the affinity to PqsBC decreased (Figure 22).

The iodine-substituted derivative $\mathbf{5 4}$ showed both, a high PqsR, as well as a high PqsBC activity. Exchanging the electron-withdrawing nitro functionality with an electron-donating methyl group turned the PqsR antagonist 53 into a very potent PqsBC inhibitor while losing activity on the initial target PqsR. In addition to these mechanistic findings, it was also shown that the 

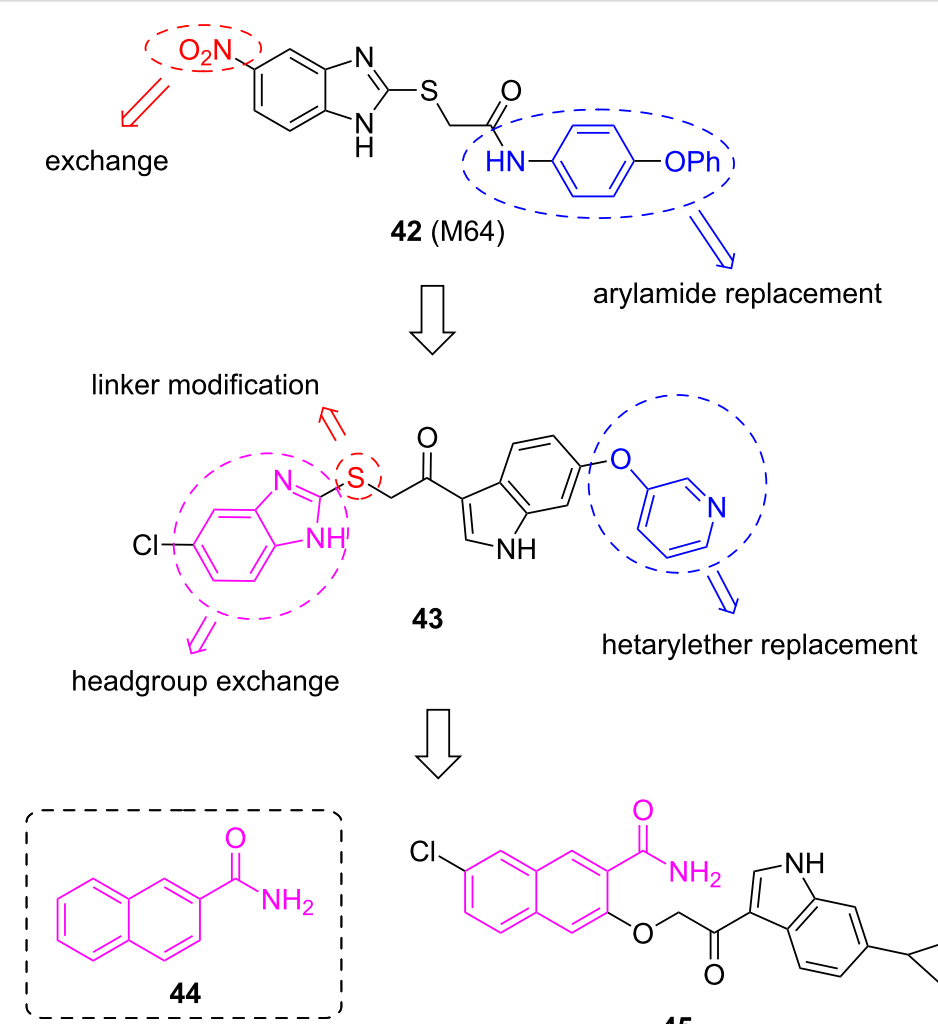<smiles>C1=CC=C1</smiles><smiles>C[As](C)(=O)OCC(=O)c1c[nH]c2cc(C3CC3)ccc12</smiles>

Figure 20: M64 (42) as the starting point for further optimization leading to $\mathbf{4 3}$, which was further modified and merged with the fragment 44 to give compound 45 .<smiles>[R]NC(=O)c1ccc([R])cc1</smiles>

$46 \mathrm{R}^{1}=\mathrm{Cl}, \mathrm{R}^{2}=\mathrm{H}$

$47 \mathrm{R}^{1}=t-\mathrm{Bu}, \mathrm{R}^{2}=\mathrm{H}$

$48 \mathrm{R}^{1}=t-\mathrm{Bu}, \mathrm{R}^{2}=\mathrm{OH}$<smiles>[R]c1cccc(-c2nnc(N)o2)c1</smiles>

$49 \mathrm{R}=\mathrm{CF}_{3}$

$50 \mathrm{R}=\mathrm{Br}$

$51 \mathrm{R}=\mathrm{CN}$

Figure 21: Hit fragments from the benzamide (47-48) and oxadiazole class (49-51).

dual inhibitors are capable of rescuing human lung epithelial cells and macrophages at a concentration of $50 \mu \mathrm{M}$ in cell-based infection models. Also antibiotic activity of meropenem (dose: $10 \mu \mathrm{g} / \mathrm{mL}$ ) in presence of $10 \mu \mathrm{M}$ of dual inhibitors could be partially reinstalled.

\section{PqsD/PqsR}

Thomann et al. showed that combining a PqsD and a PqsR activity synergistically affects pyocyanin production. Based on these results combining fragments from a PqsR and a PqsD inhibitor belonging to a sulfonyl-pyrimidine class, compound $\mathbf{5 6}$ was generated and its ability to reduce pyocyanin evaluated

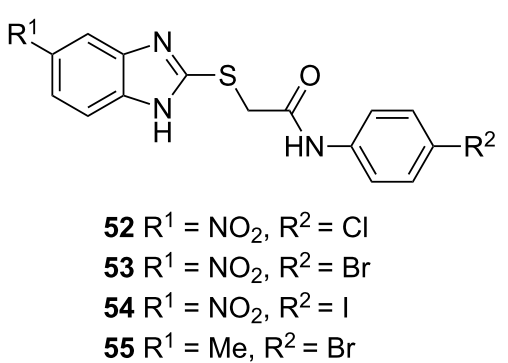

Figure 22: Structures of dual inhibitors 52-55.

(Figure 23) [84]. While exhibiting $\mathrm{IC}_{50}$ values of $15 \mu \mathrm{M}$ on PqsR and $21 \mu \mathrm{M}$ on PqsD, the compound was able to inhibit the pyocyanin production with an $\mathrm{IC}_{50}$ of $86 \mu \mathrm{M}$. Moreover 56 also proved to be efficient in blocking pyoverdine production, another important P.aeruginosa virulence factor. When applied at a concentration of $500 \mu \mathrm{M}$ less than $10 \%$ of pyoverdine production was remaining. At $100 \mu \mathrm{M}$ the pyoverdine amount was cut to a half. Since also the levels of extracellular DNA could be reduced to a minimum with their dual inhibitor, the group investigated the effect of adding $\mathbf{5 6}$ to ciprofloxacin. The combination of this QSI together with the antibiotic significantly increased antibiofilm activity at the used concentrations 
$([\mathrm{CIPX}]=1 \mu \mathrm{M},[56]=50 \mu \mathrm{M})$. The compound also proved to be active in a Galleria melonella survival assay being capable of ensuring survival up to more than $50 \%$ after $4.5 \mathrm{~d}$ post-infection at a dosage of $1.25 \mathrm{nmol}$ compared to untreated PA14infected larvae.

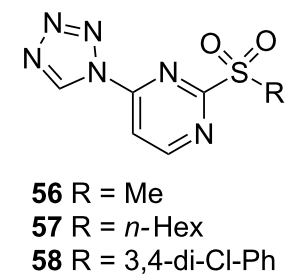

Figure 23: Sulfonyl pyrimidines $\mathbf{5 6 - 5 8}$ acting as dual PqsD/PqsR inhibitors.

Following the dual inhibitor concept, the class of sulfonylpyrimidines further afforded compounds $\mathbf{5 7}$ and $\mathbf{5 8}$ with promising activity. While PqsR activity slightly decreased (50 $\mu \mathrm{M}$ and $24 \pm 5 \mu \mathrm{M}$, respectively) 57 exhibited an $\mathrm{IC}_{50}$ of $1.7 \mu \mathrm{M}$ and 58 displayed sub-micromolar activity of $0.4 \pm 0.1 \mu \mathrm{M}$. The effects on biofilm formation and eDNA release were evaluated at a concentration of $100 \mu \mathrm{M}$. Even if $\mathbf{5 7}$ was less potent on both PqsR and PqsD compared to 58, it turned out to be more efficient in inhibiting biofilm production. When assessed on their ability to reduce extracellular DNA all three compounds were equally potent. Nevertheless compound $\mathbf{5 8}$ only showed a weak effect on the inhibition of pyocyanin (14\% inhibition at $100 \mu \mathrm{M})$ [85].

\section{Conclusion}

In the past decade, the pqs QS system of P. aeruginosa has attracted increasing interest by academic researchers. This is certainly due to its prominent involvement in virulence regulation of this important Gram-negative pathogen. Among the various pathoblocker strategies, targeting a master regulator of pathogenicity traits appears to have huge translational potential. Hitting an array of virulence mechanisms at once instead of addressing just singular factor holds great promise for future discovery and development of pqs-targeting QSI. Compared to the other QS systems present in P. aeruginosa the pqs system is lacking some of the liabilities associated with the las and the rhl systems. The former AHL-dependent regulatory circuit has been described to be the first QS system to get lost upon chronification of $P$. aeruginosa infections [86]. However, chronic lung infections are one of the major indications with a very high medical need. In the case of addressing the rhl system, a nonunidirectional virulence modulatory effect is observed. Agonists of RhlR reduce pyocyanin, but induce rhamnolipid production, while antagonists have the inverted effect [87]. This raises some concerns about the applicability of RhlR as an effective 'standalone' pathoblocker target. A combination of rhl- and pqstargeting QSI, however, seemed to provide promising and clearcut antivirulence effects [88]. Finally, the potential of iqstargeting approaches remains to be investigated as more insight in the function of this rather recently discovered regulator is needed. The pqs system is active in chronically infected cystic fibrosis patients and, according to the current knowledge, blockade of this master regulator delivers an unambiguous antivirulence effect.

In terms of published research, the most studied molecular targets within the pqs system are the signal molecule synthase PqsD and the receptor PqsR (MvfR), while in the latter case projects are currently in a clearly more advanced stage. When comparing the reported antivirulence effects of PqsD- and PqsR-targeting QSI, evidence is growing that hitting the transcriptional regulator results in more pronounced pathoblocking effects than addressing the biosynthetic enzyme cascade. However, a synergistic effect for dual-target inhibitors hitting PqsR and PqsD or PqsBC simultaneously has been described $[68,84]$. Additionally, the authors believe that attempts to effectively target PqsE are still worthwhile pursuing, given its prominent involvement in pqs virulence regulation. However, this would require elucidating the still unknown mechanism behind its regulatory function.

In order to translate the promising hit and lead compounds described above into the clinic, continuous discovery and development efforts are required. Especially the lead optimization stage is strongly dependent on integrated medicinal chemistry and biological profiling teams. In addition to potency considerations, drug-like properties aiming at favorable pharmacokinetics move into the focus [89]. Due to the complex nature of virulence phenotype assays as well as ADME/T testing cascades assembling the required teams, expertise, and resources might be a challenge especially for academic groups. Hence, often proclaimed drug discovery timelines for target-tocandidate projects of about 6 years or less [90] are quite unrealistic in this field. This actually underpins the urgency for current anti-infective discovery efforts to enable refilling the pipeline in due time before available treatment options run out. However, we believe the translational perspective for such pathoblockers is quite promising. Specifically, it has been shown that PqsR-targeting QSI are able to increase the susceptibility of $P$. aeruginosa biofilms against antibiotics [78]. Hence, adjunctive treatment approaches where a conventional backbone antibiotic therapy is potentiated by pathoblocking agents appears quite attractive. In analogy to current antiviral and anticancer strategies, more personalized pathogen-specific drug combinations should be pursued also in the bacterial infections 
field. As a consequence, more advanced diagnostic tools have to be devised to enable fast and reliable analysis of the pathogen and its resistance profile. We are curious what future research will uncover in this important, yet underexploited, drug discovery field and believe exploring such strategies further will be a worthwhile endeavour.

\section{Acknowledgements}

We are grateful to Rolf W. Hartmann for his generous and persistent support and guiding expertise.

\section{ORCID ${ }^{\circledR}$ iDs}

Martin Empting - https://orcid.org/0000-0002-0503-5830

\section{References}

1. Price, L.; Gozdzielewska, L.; Young, M.; Smith, F.; MacDonald, J.; McParland, J.; Williams, L.; Langdridge, D.; Davis, M.; Flowers, P. J. Antimicrob. Chemother. 2018, 73, 1464-1478. doi:10.1093/jac/dky076

2. Ventola, L. C. Pharm. Ther. 2015, 40, 277-283.

3. Coates, A. R. M.; Halls, G.; Hu, Y. Br. J. Pharmacol. 2011, 163, 184-194. doi:10.1111/j.1476-5381.2011.01250.x

4. WHO. An analysis of the antibacterial clinical development pipeline, including tuberculosis. http://www.who.int/medicines/areas/rational_use/antibacterial_agents_ clinical_development/en/ (accessed July 30, 2018).

5. Wagner, S.; Sommer, R.; Hinsberger, S.; Lu, C.; Hartmann, R. W.; Empting, M.; Titz, A. J. Med. Chem. 2016, 59, 5929-5969. doi:10.1021/acs.jmedchem.5b01698

6. Li, X.-H.; Lee, J.-H. J. Microbiol. (Seoul, Repub. Korea) 2017, 55, 753-766. doi:10.1007/s12275-017-7274-x

7. Żelechowska, P.; Agier, J.; Kozłowska, E.; Brzezińska-Błaszczyk, E. Przegl. Lek. 2016, 73, 334-339.

8. Mühlen, S.; Dersch, P. Anti-virulence Strategies to Target Bacterial Infections. In How to Overcome the Antibiotic Crisis. Current Topics in Microbiology and Immunology; Stadler, M.; Dersch, P., Eds.; Springer: Cham, 2015; Vol. 398, pp 147-183. doi:10.1007/82_2015_490

9. Dickey, S. W.; Cheung, G. Y. C.; Otto, M. Nat. Rev. Drug Discovery 2017, 16, 457-471. doi:10.1038/nrd.2017.23

10. Kufel, W. D.; Devanathan, A. S.; Marx, A. H.; Weber, D. J.; Daniels, L. M. Pharmacotherapy 2017, 37, 1298-1308. doi:10.1002/phar.1990

11. Soukarieh, F.; Williams, P.; Stocks, M. J.; Camara, M. J. Med. Chem. 2018, in press. doi:10.1021/acs.jmedchem.8b00540

12. WHO. Global priority list of antibiotic-resistant bacteria to guide research, discovery, and development of new antibiotics. http://www.who.int/medicines/publications/global-priority-list-antibiotic-r esistant-bacteria/en/ (accessed July 30, 2018).

13. Schweizer, H. P. GMR, Genet. Mol. Res. 2003, 2, 48-62.

14. Strateva, T.; Yordanov, D. J. Med. Microbiol. 2009, 58, 1133-1148. doi:10.1099/jmm.0.009142-0

15. Breidenstein, E. B. M.; de la Fuente-Núñez, C.; Hancock, R. E. W. Trends Microbiol. 2011, 19, 419-426. doi:10.1016/j.tim.2011.04.005

16. Golemi-Kotra, D. Pseudomonas Infections. xPharm: The Comprehensive Pharmacology Reference; Elsevier, 2008; pp 1-8.

17. Bodey, G. P.; Bolivar, R.; Fainstein, V.; Jadeja, L. Rev. Infect. Dis. 1983, 5, 279-313. doi:10.1093/clinids/5.2.279
18. da Silva Filho, L. V. R. F.; de Agujar Ferreira, F.; Reis, F. J. C.; de Britto, M. C. A.; Levy, C. E.; Clark, O.; Ribeiro, J. D. J. Bras. Pneumol. 2013, 39, 495-512. doi:10.1590/S1806-37132013000400015

19. Crull, M. R.; Ramos, K. J.; Caldwell, E.; Mayer-Hamblett, N.; Aitken, M. L.; Goss, C. H. BMC Pulm. Med. 2016, 16, 176. doi:10.1186/s12890-016-0333-y

20. Sordé, R.; Pahissa, A.; Rello, J. Infect. Drug Resist. 2011, 4, 31-41. doi:10.2147/IDR.S16263

21. Barr, H. L.; Halliday, N.; Barrett, D. A.; Williams, P.; Forrester, D. L.; Peckham, D.; Williams, K.; Smyth, A. R.; Honeybourne, D.; Whitehouse, J. L.; Nash, E. F.; Dewar, J.; Clayton, A.; Knox, A. J.; Cámara, M.; Fogarty, A. W. J. Cystic Fibrosis 2017, 16, 230-238. doi:10.1016/j.jcf.2016.10.005

22. Lee, J.; Zhang, L. Protein Cell 2015, 6, 26-41. doi:10.1007/s13238-014-0100-x

23. Li, S.; Chen, S.; Fan, J.; Cao, Z.; Ouyang, W.; Tong, N.; Hu, X.; Hu, J.; Li, P.; Feng, Z.; Huang, X.; Li, Y.; Xie, M.; He, R.; Jian, J.; Wu, B.; Xu, C.; Wu, W.; Guo, J.; Lin, J.; Sun, P. Eur. J. Med. Chem. 2018, 145, 64-73. doi:10.1016/j.ejmech.2017.12.076

24. Dubern, J.-F.; Diggle, S. P. Mol. BioSyst. 2008, 4, 882-888. doi:10.1039/b803796p

25. Coleman, J. P.; Hudson, L. L.; McKnight, S. L.; Farrow, J. M., III; Calfee, M. W.; Lindsey, C. A.; Pesci, E. C. J. Bacteriol. 2008, 190, 1247-1255. doi:10.1128/JB.01140-07

26. Zhang, Y.-M.; Frank, M. W.; Zhu, K.; Mayasundari, A.; Rock, C. O. J. Biol. Chem. 2008, 283, 28788-28794. doi:10.1074/jbc.M804555200

27. Dulcey, C. E.; Dekimpe, V.; Fauvelle, D.-A.; Milot, S.; Groleau, M.-C.; Doucet, N.; Rahme, L. G.; Lépine, F.; Déziel, E. Chem. Biol. 2013, 20 , 1481-1491. doi:10.1016/j.chembiol.2013.09.021

28. Hutter, M. C.; Brengel, C.; Negri, M.; Henn, C.; Zimmer, C.; Hartmann, R. W.; Empting, M.; Steinbach, A. J. Mol. Model. 2014, 20, 2255. doi:10.1007/s00894-014-2255-z

29. Drees, S. L.; Fetzner, S. Chem. Biol. 2015, 22, 611-618. doi:10.1016/j.chembiol.2015.04.012

30. Witzgall, F.; Depke, T.; Hoffmann, M.; Empting, M.; Brönstrup, M.; Müller, R.; Blankenfeldt, W. ChemBioChem 2018, 19, 1531-1544. doi:10.1002/cbic. 201800153

31. Drees, S. L.; Li, C.; Prasetya, F.; Saleem, M.; Dreveny, I.; Williams, P.; Hennecke, U.; Emsley, J.; Fetzner, S. J. Biol. Chem. 2016, 291, 6610-6624. doi:10.1074/jbc.M115.708453

32. Schertzer, J. W.; Brown, S. A.; Whiteley, M. Mol. Microbiol. 2010, 77, 1527-1538. doi:10.1111/j.1365-2958.2010.07303.x

33. Rampioni, G.; Falcone, M.; Heeb, S.; Frangipani, E.; Fletcher, M. P.; Dubern, J.-F.; Visca, P.; Leoni, L.; Cámara, M.; Williams, P. PLoS Pathog. 2016, 12, e1006029. doi:10.1371/journal.ppat.1006029

34. Lin, J.; Cheng, J.; Wang, Y.; Shen, X. Front. Cell. Infect. Microbiol. 2018, 8, No. 230. doi:10.3389/fcimb.2018.00230

35. Maura, D.; Hazan, R.; Kitao, T.; Ballok, A. E.; Rahme, L. G. Sci. Rep. 2016, 6, No. 34083. doi:10.1038/srep34083

36. Legendre, C.; Reen, F. J.; Mooij, M. J.; McGlacken, G. P.; Adams, C.; O'Gara, F. Infect. Immun. 2012, 80, 3985-3992. doi:10.1128/IAI.00554-12

37. Kim, K.; Kim, Y. U.; Koh, B. H.; Hwang, S. S.; Kim, S.-H.; Lépine, F.; Cho, Y.-H.; Lee, G. R. Immunology 2010, 129, 578-588. doi:10.1111/j.1365-2567.2009.03160.x

38. Hazan, R.; Que, Y. A.; Maura, D.; Strobel, B.; Majcherczyk, P. A.; Hopper, L. R.; Wilbur, D. J.; Hreha, T. N.; Barquera, B.; Rahme, L. G. Curr. Biol. 2016, 26, 195-206. doi:10.1016/j.cub.2015.11.056 
39. Gruber, J. D.; Chen, W.; Parnham, S.; Beauchesne, K.; Moeller, P.; Flume, P. A.; Zhang, Y.-M. PeerJ 2016, 4, e1495. doi:10.7717/peerj.1495

40. Que, Y.-A.; Hazan, R.; Strobel, B.; Maura, D.; He, J.; Kesarwani, M.; Panopoulos, P.; Tsurumi, A.; Giddey, M.; Wilhelmy, J.; Mindrinos, M. N.; Rahme, L. G. PLoS One 2013, 8, e80140. doi:10.1371/journal.pone.0080140

41. Hall, S.; McDermott, C.; Anoopkumar-Dukie, S.; McFarland, A. J.; Forbes, A.; Perkins, A. V.; Davey, A. K.; Chess-Williams, R.; Kiefel, M. J.; Arora, D.; Grant, G. D. Toxins 2016, 8, No. 236. doi:10.3390/toxins8080236

42. Allen, L.; Dockrell, D. H.; Pattery, T.; Lee, D. G.; Cornelis, P.; Hellewell, P. G.; Whyte, M. K. B. J. Immunol. 2005, 174, 3643-3649. doi:10.4049/jimmunol.174.6.3643

43. Rada, B.; Jendrysik, M. A.; Pang, L.; Hayes, C. P.; Yoo, D.-G.; Park, J. J.; Moskowitz, S. M.; Malech, H. L.; Leto, T. L. PLoS One 2013, 8, e54205. doi:10.1371/journal.pone.0054205

44. Arai, H. Front. Microbiol. 2011, 2, No. 103. doi:10.3389/fmicb.2011.00103

45. Lépine, F.; Dekimpe, V.; Lesic, B.; Milot, S.; Lesimple, A.; Mamer, O. A.; Rahme, L. G.; Déziel, E. Biol. Chem. 2007, 388, 839-845. doi:10.1515/BC.2007.100

46. Witzgall, F.; Ewert, W.; Blankenfeldt, W. ChemBioChem 2017, 18, 2045-2055. doi:10.1002/cbic.201700374

47. Lesic, B.; Lépine, F.; Déziel, E.; Zhang, J.; Zhang, Q.; Padfield, K.; Castonguay, M.-H.; Milot, S.; Stachel, S.; Tzika, A. A.; Tompkins, R. G.; Rahme, L. G. PLoS Pathog. 2007, 3, 1229-1239. doi:10.1371/journal.ppat.0030126

48. Ji, C.; Sharma, I.; Pratihar, D.; Hudson, L. L.; Maura, D.; Guney, T.; Rahme, L. G.; Pesci, E. C.; Coleman, J. P.; Tan, D. S. ACS Chem. Biol. 2016, 11, 3061-3067. doi:10.1021/acschembio.6b00575

49. Bera, A. K.; Atanasova, V.; Robinson, H.; Eisenstein, E.; Coleman, J. P.; Pesci, E. C.; Parsons, J. F. Biochemistry 2009, 48, 8644-8655. doi:10.1021/bi9009055

50. Pistorius, D.; Ullrich, A.; Lucas, S.; Hartmann, R. W.; Kazmaier, U.; Müller, R. ChemBioChem 2011, 12, 850-853. doi:10.1002/cbic.201100014

51. Weidel, E.; de Jong, J. C.; Brengel, C.; Storz, M. P.; Braunshausen, A.; Negri, M.; Plaza, A.; Steinbach, A.; Müller, R.; Hartmann, R. W. J. Med. Chem. 2013, 56, 6146-6155. doi:10.1021/jm4006302

52. Hinsberger, S.; de Jong, J. C.; Groh, M.; Haupenthal, J.; Hartmann, R. W. Eur. J. Med. Chem. 2014, 76, 343-351. doi:10.1016/j.ejmech.2014.02.014

53. Hinsberger, S.; Hüsecken, K.; Groh, M.; Negri, M.; Haupenthal, J.; Hartmann, R. W. J. Med. Chem. 2013, 56, 8332-8338. doi:10.1021/jm400485e

54.Storz, M. P.; Maurer, C. K.; Zimmer, C.; Wagner, N.; Brengel, C.; de Jong, J. C.; Lucas, S.; Müsken, M.; Häussler, S.; Steinbach, A.; Hartmann, R. W. J. Am. Chem. Soc. 2012, 134, 16143-16146. doi:10.1021/ja3072397

55. Storz, M. P.; Brengel, C.; Weidel, E.; Hoffmann, M.; Hollemeyer, K.; Steinbach, A.; Müller, R.; Empting, M.; Hartmann, R. W. ACS Chem. Biol. 2013, 8, 2794-2801. doi:10.1021/cb400530d

56. Storz, M. P.; Allegretta, G.; Kirsch, B.; Empting, M.; Hartmann, R. W. Org. Biomol. Chem. 2014, 12, 6094-6104. doi:10.1039/c4ob00707g

57. Sahner, J. H.; Brengel, C.; Storz, M. P.; Groh, M.; Plaza, A.; Müller, R.; Hartmann, R. W. J. Med. Chem. 2013, 56, 8656-8664. doi:10.1021/jm401102e
58. Sahner, J. H.; Empting, M.; Kamal, A.; Weidel, E.; Groh, M.; Börger, C.; Hartmann, R. W. Eur. J. Med. Chem. 2015, 96, 14-21. doi:10.1016/j.ejmech.2015.04.007

59. Allegretta, G.; Weidel, E.; Empting, M.; Hartmann, R. W. Eur. J. Med. Chem. 2015, 90, 351-359. doi:10.1016/j.ejmech.2014.11.055

60. Weidel, E.; Negri, M.; Empting, M.; Hinsberger, S.; Hartmann, R. W. Future Med. Chem. 2014, 6, 2057-2072. doi:10.4155/fmc.14.142

61. Thomann, A.; Zapp, J.; Hutter, M.; Empting, M.; Hartmann, R. W. Org. Biomol. Chem. 2015, 13, 10620-10630. doi:10.1039/c5ob01006c

62. Prothiwa, M.; Szamosvári, D.; Glasmacher, S.; Böttcher, T. Beilstein J. Org. Chem. 2016, 12, 2784-2792. doi:10.3762/bjoc.12.277

63. Sangshetti, J. N.; Khan, F. A. K.; Patil, R. H.; Marathe, S. D.; Gade, W. N.; Shinde, D. B. Bioorg. Med. Chem. Lett. 2015, 25, 874-880. doi:10.1016/j.bmcl.2014.12.063

64. Farrow, J. M., III; Sund, Z. M.; Ellison, M. L.; Wade, D. S.; Coleman, J. P.; Pesci, E. C. J. Bacteriol. 2008, 190, 7043-7051. doi:10.1128/JB.00753-08

65. Rampioni, G.; Pustelny, C.; Fletcher, M. P.; Wright, V. J.; Bruce, M.; Rumbaugh, K. P.; Heeb, S.; Cámara, M.; Williams, P. Environ. Microbiol. 2010, 12, 1659-1673. doi:10.1111/j.1462-2920.2010.02214.x

66. Zender, M.; Witzgall, F.; Drees, S. L.; Weidel, E.; Maurer, C. K.; Fetzner, S.; Blankenfeldt, W.; Empting, M.; Hartmann, R. W. ACS Chem. Biol. 2016, 11, 1755-1763. doi:10.1021/acschembio.6b00156

67. Kesarwani, M.; Hazan, R.; He, J.; Que, Y.; Apidianakis, Y.; Lesic, B.; Xiao, G.; Dekimpe, V.; Milot, S.; Deziel, E.; Lépine, F.; Rahme, L. G. PLoS Pathog. 2011, 7, e1002192. doi:10.1371/journal.ppat.1002192

68. Maura, D.; Drees, S. L.; Bandyopadhaya, A.; Kitao, T.; Negri, M.; Starkey, M.; Lesic, B.; Milot, S.; Déziel, E.; Zahler, R.; Pucci, M.; Felici, A.; Fetzner, S.; Lépine, F.; Rahme, L. G. ACS Chem. Biol. 2017, 12, 1435-1443. doi:10.1021/acschembio.6b01139

69. Allegretta, G.; Maurer, C. K.; Eberhard, J.; Maura, D.; Hartmann, R. W.; Rahme, L.; Empting, M. Front. Microbiol. 2017, 8, No. 924 doi:10.3389/fmicb.2017.00924

70. Rahme, L.; Lepine, F.; Starkey, M.; Lesic-Arsic, B. Antibiotic tolerance inhibitors. WO Patent WO2012116010A3, Oct 26, 2012.

71. Kamal, A. A. M.; Petrera, L.; Eberhard, J.; Hartmann, R. W. Org. Biomol. Chem. 2017, 15, 4620-4630. doi:10.1039/c7ob00263g

72. Lu, C.; Kirsch, B.; Zimmer, C.; de Jong, J. C.; Henn, C.; Maurer, C. K.; Müsken, M.; Häussler, S.; Steinbach, A.; Hartmann, R. W. Chem. Biol. 2012, 19, 381-390. doi:10.1016/j.chembiol.2012.01.015

73. Lu, C.; Maurer, C. K.; Kirsch, B.; Steinbach, A.; Hartmann, R. W. Angew. Chem., Int. Ed. 2014, 53, 1109-1112. doi:10.1002/anie.201307547

74. Lu, C.; Kirsch, B.; Maurer, C. K.; de Jong, J. C.; Braunshausen, A.; Steinbach, A.; Hartmann, R. W. Eur. J. Med. Chem. 2014, 79, 173-183. doi:10.1016/j.ejmech.2014.04.016

75. Shanahan, R.; Reen, F. J.; Cano, R.; O’Gara, F.; McGlacken, G. P. Org. Biomol. Chem. 2017, 15, 306-310. doi:10.1039/c6ob01930g

76. Ilangovan, A.; Fletcher, M.; Rampioni, G.; Pustelny, C.; Rumbaugh, K.; Heeb, S.; Cámara, M.; Truman, A.; Chhabra, S. R.; Emsley, J.; Williams, P. PLoS Pathog. 2013, 9, e1003508. doi:10.1371/journal.ppat.1003508

77. Starkey, M.; Lepine, F.; Maura, D.; Bandyopadhaya, A.; Lesic, B.; He, J.; Kitao, T.; Righi, V.; Milot, S.; Tzika, A.; Rahme, L. PLoS Pathog. 2014, 10, e1004321. doi:10.1371/journal.ppat.1004321

78. Maura, D.; Rahme, L. G. Antimicrob. Agents Chemother. 2017, 61, e01362-17. doi:10.1128/AAC.01362-17 
79. Kitao, T.; Lepine, F.; Babloudi, S.; Walte, F.; Steinbacher, S.;

Maskos, K.; Blaesse, M.; Negri, M.; Pucci, M.; Zahler, B.; Felici, A.;

Rahme, L. G. mBio 2018, 9, e02158-17. doi:10.1128/mBio.02158-17

80. Zahler, R.; Cui, D.; Zhou, D. Carbonyl linked bicyclic heteroaryl $\mathrm{N}$-benzimidazoles and analogs as antibiotic tolerance inhibitors. WO Patent WO2016040764A1, March 17, 2016.

81. Zahler, R. Aryloxyacetylindoles and analogs as antibiotic tolerance inhibitors. WO Patent WO2016112088A1, July 14, 2016.

82. Zender, M.; Klein, T.; Henn, C.; Kirsch, B.; Maurer, C. K.; Kail, D.; Ritter, C.; Dolezal, O.; Steinbach, A.; Hartmann, R. W. J. Med. Chem. 2013, 56, 6761-6774. doi:10.1021/jm400830r

83. Klein, T.; Henn, C.; de Jong, J. C.; Zimmer, C.; Kirsch, B.; Maurer, C. K.; Pistorius, D.; Müller, R.; Steinbach, A.; Hartmann, R. W. ACS Chem. Biol. 2012, 7, 1496-1501. doi:10.1021/cb300208g

84. Thomann, A.; de Mello Martins, A. G. G.; Brengel, C.; Empting, M.; Hartmann, R. W. ACS Chem. Biol. 2016, 11, 1279-1286. doi:10.1021/acschembio.6b00117

85. Thomann, A.; Brengel, C.; Börger, C.; Kail, D.; Steinbach, A.; Empting, M.; Hartmann, R. W. ChemMedChem 2016, 11, 2522-2533. doi:10.1002/cmdc.201600419

86. Bjarnsholt, T.; Jensen, P. Ø.; Jakobsen, T. H.; Phipps, R.; Nielsen, A. K.; Rybtke, M. T.; Tolker-Nielsen, T.; Givskov, M.; Høiby, N.; Ciofu, O. PLoS One 2010, 5, e10115. doi:10.1371/journal.pone.0010115

87. Welsh, M. A.; Eibergen, N. R.; Moore, J. D.; Blackwell, H. E. J. Am. Chem. Soc. 2015, 137, 1510-1519. doi:10.1021/ja5110798

88. Welsh, M. A.; Blackwell, H. E. Cell Chem. Biol. 2016, 23, 361-369. doi:10.1016/j.chembiol.2016.01.006

89. Kerns, E. H.; Di, L. Drug-like properties. Concepts, structure design and methods: from ADME to toxicity optimization; Academic Press: Amsterdam, London, 2008.

90. Maqbool, F.; Abid, A.; Ahmed, I. Int. J. Pharm. 2017, 13, 773-784. doi:10.3923/ijp.2017.773.784

\section{License and Terms}

This is an Open Access article under the terms of the Creative Commons Attribution License (http://creativecommons.org/licenses/by/4.0). Please note that the reuse, redistribution and reproduction in particular requires that the authors and source are credited.

The license is subject to the Beilstein Journal of Organic Chemistry terms and conditions:

(https://www.beilstein-journals.org/bjoc)

The definitive version of this article is the electronic one which can be found at: $\underline{\text { doi:10.3762/bjoc. } 14.241}$ 